Успехи физ. мет. / Usp. Fiz. Met. 2014, т. 15, сc. 173-212 Оттиски доступны непосредственно от издателя Фотокопирование разрешено только

в соответствии с лицензией (с) 2014 ИМФ (Институт металлофизики им. Г. В. Курдюмова НАН Украины)

Напечатано в Украине.

PACS numbers: 61.50.Ks, 61.72.Bb, 61.72.Lk, 62.20.fg, 64.60.Q-, 81.07.Bc, 81.30.Kf

\title{
Nucleation and Martensitic Transformation in Subjects of Small Dimensions
}

\author{
V. A. Lobodyuk
}

G. V. Kurdyumov Institute for Metal Physics, N.A.S. of Ukraine, 36 Academician Vernadsky Blvd. UA-03680 Kyiv-142, Ukraine

The existing models and schemes of the martensitic phase nucleation are considered in the review. Theoretical and experimental works devoted to the nucleation of the martensitic crystals in different metals are discussed and analysed. The parameters and processes of the martensitic transformation in such subjects of small dimensions as particles, porous materials, thin films, nanoparticles, and nanomaterials are also considered and discussed.

В огляді розглядаються наявні моделі та схеми зародження мартенситних фаз, обговорюються теоретичні й експериментальні роботи, присвячені зародженню кристалів мартенситу в різних металах. Розглядаються й обговорюються параметри та процеси мартенситного перетворення у таких об’єктах малих розмірів як частинки, порошкові матеріяли, тонкі плівки, наночастинки та наноматеріяли.

В обзоре рассматриваются существующие модели и схемы зарождения мартенситных фаз, обсуждаются теоретические и экспериментальные работы, посвящённые зарождению кристаллов мартенсита в различных металлах. Рассматриваются и обсуждаются параметры и процессы мартенситного превращения в таких объектах малых размеров как частицы, порошковые материалы, тонкие плёнки, наночастицы и наноматериалы.

Keywords: alloys, crystals, dimensions, nanoparticles, dislocation, nucleation, nucleus, martensitic transformation, martensite.

(Received September 26, 2014)

\section{CONTENTS}

1. Introduction

2. Nucleation of martensite 
2.1. Theoretical aspects of nucleation of martensite

2.2. Experimental confirmation of presence of martensitic nuclei 3. Martensitic transformation in the subjects of small dimensions

3.1. Martensitic transformation in particles and inclusions

3.2. Martensitic transformation in powder materials

3.3. Martensitic transformation in thin films

3.4. Martensitic transformation in nanocrystals and nanomaterials

4. Conclusion

\section{INTRODUCTION}

Martensitic transformation (MT) in the subjects of small dimensions takes place with essential peculiarities in comparison to massive materials that is stipulated for so named 'sized factor'. Consideration of these peculiarities is needed to begin from problems of nucleation of martensitic phase and martensitic crystals in parent phase because beginning from nucleation and during future growth of martensitic crystals these peculiarities arise, and they are conditioned by own mechanism of martensitic transformation. This is caused by considerable influence of transformation volume on proceeding of new phase nucleation processes and following phase transformation [1].

Problems of nucleation of new phase during MT are sufficiently difficult and least solved despite of many years investigations of the nature and mechanism MT in metals and alloys which takes place during lowering of temperature or under different external influences (stress, deformation, magnetic field, irradiation) [2]. Apparently, these problems are concerned with that besides some suppositions there are no reliable experimental results on the existence and structure of martensitic nuclei.

There are some investigations devoted to consideration of models and patterns of martensite crystal nucleation and following growth. Theoretical studies of these processes also fulfilled. However, these models and patterns are proposed for definite MT in definite alloys, most often for MT in the Fe and Co alloys. Generalized models for the whole types of MT did not elaborate and did not propose up to now. Dislocation model of martensite phase nucleation in cobalt was historically first [3]. Later some others for different types of MT were proposed. Consideration of these models and schemes will be made in the next section.

G. V. Kurdyumov presented principal statements about the nature of martensitic transformations in fundamental work [4]. Mechanism and kinetic peculiarities of this type phase transformation were also considered and discussed in this work. There were concluded that, if MT proceeded without content changes, these trans- 
formations can be regarded as transitions in single component systems similarly polymorphic transformations in pure metals. Then, as in case of other phase transitions, MT must take place due to formation of nuclei and their following growth during change of external conditions: temperature, pressure, radiation. This conclusion gives possibility to use for consideration of MT basic postulates used for crystallization of liquid of one-component system.

The principal existing views of the processes of martensitic phase nucleus formation and future growth, different models of nucleus formation will be considered and discussed in this review. Theoretical and experimental works devoted to these problems will be also discussed. Martensitic transformations in the subjects of small dimensions as porous materials formed during aging particles, different types of thin films, nanoparticles and nanomaterials will be discussed in connection with the peculiarities of MT and their great practical interest. Latter stipulated for that structure and state of these materials must result in many peculiarities in proceeding of MT and in corresponding changing of properties that is often conditioned by sized factor.

\section{NUCLEATION OF MARTENSITE}

\subsection{Theoretical Aspects of Nucleation of Martensite}

It was supposed that in structure of the parent phase small sections with crystal structure of new (martensitic) phase could arise [4]. During decreasing of temperature lower than equilibrium temperature, these sections will serve as nuclei of new phase. Only nuclei with sizes greater critical one will be grow. Critical size nucleus which can grow is defined by the undercooling degree $\Delta T=T_{0}-T$, where $T_{0}$-equilibrium temperature of parent and martensitic phases, $T$-current temperature. Essential amount of critical size nuclei appear only under definite undercooling $\Delta T=T_{0}-T_{\mathrm{M}}$, where $T_{\mathrm{M}}$ is boundary of instability (temperature of beginning of martensitic transformation $M_{\mathrm{s}}$ ).

In the case of crystallization of liquid, amount of appearing in time unit nuclei is defined by the following equation [5]:

$$
I=K \exp \{-U /(k T)\} \exp \left\{-R_{\mathrm{m}} /(k T)\right\},
$$

where $U$-activation energy, $R_{\mathrm{m}}$-formation work of nucleus capable to grow, $K-T$-independent coefficient.

During MT, activation energy is small, therefore first multiplier is near 1 , and amount of nuclei is defined by the work of nuclei formation $R_{\mathrm{m}}$. Near equilibrium temperature, the work $R_{\mathrm{m}}$ is large 
and quickly decreases with growing of deflection from $T_{0}$. Only under some undercooling and approaching to the metastable boundary (in the case of MT to temperature $M_{\mathrm{s}}$ ), it is possible of appearing of noticeable number of nuclei [5]. Under holding at temperature below $M_{\mathrm{s}}$, the rate of nucleus formation decreases quickly, therefore MT ceases. For next transformation, it is needed additional cooling under which the growth of those nuclei proceeds, which were lesser than critical sizes at higher temperature. Definite temperature below $M_{\mathrm{s}}$ own size critical nucleus corresponds too.

Experimental results testify that dependences of nucleus number and volume of martensitic phase on temperature have the same (identical) view [4]. In this work, the idea about frozen concentration fluctuations of the solid solution in which MT takes place and on dependence of the equilibrium temperature $T_{0}$ on the concentration of elements advanced. Critical nucleus formation probability depends on the concentration in definite areas. This probability is greater in the area with concentration lower than average one and is lesser in the areas with higher concentration. Such dependence is essential particularly during initial stages of MT. Under transformation progress, the influence of appeared martensite on nontransformed parts becomes more essential.

Existence up to the transformation beginning (higher $T_{0}$ ) of definite number of new phase critical nuclei is supposed also in Ref. [6]. However, the conditions and mechanism of their appearances were not explained. In this work, MT is described in the following way. Under cooling lower $M_{\mathrm{s}}$, new nuclei arise autocatalytically during transformation, their number depends on amount of martensite appeared at given temperature. During this process, a part of already existing nuclei is spent on the arising of new portions of martensite. Authors supposed that number nuclei $n_{\mathrm{i}}$ existing in $\mathrm{cm}^{3}$ in moment of time $t$ is determined by the equation:

$$
n_{\mathrm{t}}=\left(n_{\mathrm{i}}+p f-N_{\mathrm{v}}\right)(1-f),
$$

where $n_{\mathrm{i}}$ is a number of existing up to transformation nuclei, $p-$ autocatalytical factor determining the number of new arisen nuclei in $\mathrm{cm}^{3}$ (this factor does not depend on the size of initial grain and grows during temperate lowering), $f$-volume part of martensite, $N_{\mathrm{v}}$-a number of martensitic plates in unit volume. The expression $\left(n_{\mathrm{i}}+p f-N_{\mathrm{v}}\right)$ determines a number of nuclei in $1 \mathrm{~cm}^{3}$, which can grow in the time moment $t$. However, in this equation, the part of nuclei that is spent during formation of martensite in present moment does not take into account. Autocatalytic factor stipulated arising of elastic and plastic deformations during MT.

Many works devoted also to investigations of the autocatalytic 
effect during MT and to discovery nature of this effect. The results of these works confirm important influence on the mechanism of MT appearing during transformation deformations and distortions.

The rate of nucleation of new crystals in arbitrary moment of time $t$ is determined by the equation:

$$
\dot{N}=\left(n_{\mathrm{i}}+p f-N_{\mathrm{v}}\right) v \exp \left\{-\Delta W_{\mathrm{a}} /(R T)\right\},
$$

where $v$-oscillated lattice frequency $\left(10^{3} \mathrm{~cm}^{-1}\right), \Delta W_{\mathrm{a}}$-increasing of the free energy necessary for activation of the Avogadro nucleus number [6]. Authors offered to rewrite this equation to next view:

$$
\dot{N}=\left(n_{\mathrm{i}}+N_{\mathrm{v}}\right)(p \bar{v}-1) v \exp \left\{-\Delta W_{\mathrm{a}} /(R T)\right\}
$$

where $\bar{v}$-average volume of the martensitic plate. It is follow from this equation that, if $(p \bar{v}-1)=0$, the nuclei number in the unit volume remains constant at each $n_{\mathrm{i}}$ because of number expensed during the nuclei transformation equals again to the arising one at the expense of autocatalytic effect. In this case, nucleation velocity does not depend on the reaction time. Therefore, real velocity will not be to differ from actual initial nucleus velocity $\dot{N}$.

The results of numerous investigations showed that number existing up to beginning of MT nuclei does not depend on the grain sizes. It is follow from this that the boundaries do not appear the places of the preferential nucleation of the new phase crystals, at any rate at the initial transformation stages.

Growth of the preliminary existing nuclei during following cooling lower martensitic point $M_{\mathrm{s}}$ is considered also in Refs. [7, 8]. Authors of Ref. [8] supposed that, in Fe alloys, these nuclei have b.c.c. structure, their radius is equal to some tens $\mathrm{nm}$. It is supposed that semi-coherent nucleus boundary consists from some multitude of parallel dislocation loops providing the tie of nucleus with surrounding matrix. Following radial growth of nucleus takes place by moving of edge dislocation component, arising new dislocation loops at the boundary and their next transfer [8]. Nucleus thickening proceeds by the moving of screw dislocation component. Evaluations fulfilled for MT in $\mathrm{Fe}-\mathrm{Ni}-\mathrm{Mn}$ alloy showed that time formation of every next dislocation loop is decreased compared to time of previously appeared loop.

At definite stage, nucleation growth proceeds only in radial direction. As shown by evaluations, stress causing nucleus thickening are proportional to relation of semi-thickness $c$ to its radius $r: c / r$ [8]. Dependence of radial growth on stress is more complicated. For this growth, dependence on derivative $\delta \Delta G / \delta r$ is characteristic one; here, $\Delta G$-free energy change during formation martensitic particle 
(nucleus) by $r$ radius. According to suggested model, velocity of radial growth depends on nucleus size and quickly increases during martensitic crystal growth and own process of MT becomes as explosive process. Activation energy of nucleation of new dislocation loop depends also on critical nucleus size and, according to fulfilled evaluations for alloy $\mathrm{Fe}-29.3 \% \mathrm{Ni}-0.2 \% \mathrm{Mn}\left(\right.$ wt. $\%$ ) at $-15^{\circ} \mathrm{C}$, quickly decreases starting from $r=60 \mathrm{~nm}$. Nevertheless, it is difficult already to name this formation by martensitic nucleus.

Assumption about previously existing (higher $T_{0}$ ) martensitic nuclei did not find any experimental confirmations. May be, their discovery cannot be fulfilled by using modern experimental investigation methods. In addition, up to now, we have not clear definition: what is martensitic nucleus?

In Ref. [9], next mechanism of martensitic nuclei formation at transformation temperature was proposed. During MT, definite reconstruction takes place by means of the successive transformations of defects existing in material at temperature $M_{\mathrm{s}}$ into some specific defects forming martensitic nucleus. This defect may be group of 3-5 dislocations. Authors consider that proposed mechanism is in accordance with heterogeneous character of MT, crystallography of MT, in particular with orientation relationship of parent and martensitic phases, and with athermal character of martensitic transfer. Like other phase transformation, own process of martensitic nucleus formation takes place in some stages with changing of coherence level at interphase boundary from some maximum to minimum value. Authors considered the mechanisms of nucleus formation for martensitic transfer of type f.c.c. $\rightarrow$ h.c.p. (hexagonal close-packed structure), f.c.c. $\rightarrow$ b.c.c. or other type of martensitic lattice.

In the case of f.c.c. $\rightarrow$ h.c.p. transformation, the origin of defects, that during following reconstruction of the martensitic nucleus forms takes place on neighbouring close-packed plane of parent structure. These can be extraction-stacking faults. Their formation takes place spontaneously and proceeds so that the defect plane does not change own location at following stages (that is does not rotate), that provides necessary orientation relationship of two structures-parent and martensitic. Consideration of chemical (difference of free energies of parent and arising phases), deformation and surface energy of nucleus shows that during reconstruction it is energetically advantageously the splitting of the defect group existing in parent phase and appearing of defect consisting of the extracting stacking faults forming martensitic nucleus. Energy of defect consisting of $n$ planes can be written in the form:

$$
\gamma=n \rho_{\mathrm{A}}\left(\Delta G^{\text {chem }}+E^{\text {def }}\right)+2 \sigma(n),
$$


where $\rho_{\mathrm{A}}$-density of atoms in close-packed planes in moles on surface unity, a difference of chemical free energies of parent and arising phases $\Delta G^{\text {chem }}$ and deformation energy $E^{\text {def }}$ determined as molar quantities, $2 \sigma(n)$-free energy of unity area of interphase boundary 'particle-matrix'. According to classical Gibbs definition, quantities $\Delta G^{\text {chem }}$ and $E^{\text {def }}$ relate to volume properties and do not depend on nucleus size. The whole differences between the 'volume' and the nucleus consist of surface energy $\sigma$ but $\sigma$ can depend on defect thickness $n$. In this case, the equation (5) describes general defect energy.

Fulfilled evaluations showed that if the defect energy becomes negative nucleus formation takes place without barrier and process proceeds by athermal manner. Temperature $M_{\mathrm{s}}$ of the beginning of MT is determined by the biggest defect, which can transform, that is by amount $n$-quantity of close-packed planes in nucleus. The size of defect, which transforms in nucleus spontaneously for FeCrNi alloys, can be obtained from equation (5), if we set $\gamma=0$ :

$$
n^{*}=-\frac{2 \sigma}{\rho\left(\Delta G^{\text {chem }}+E^{\text {def }}\right)} .
$$

Evaluations showed that $n^{*}=7$ for $\mathrm{Fe}-16 \% \mathrm{Cr}-13 \% \mathrm{Ni}$ (wt. $\%$ ) and $n^{*}=10$ for $\mathrm{Fe}-18 \% \mathrm{Cr}-12 \% \mathrm{Ni}$ (wt.\%). As during transferring of one partial dislocation, the formation of two atom planes of h.c.p. structure takes place the defect leading to rise of martensite at $M_{\mathrm{s}}$ consists of 4 or 5 dislocations.

Besides perfect dislocations, which are dissociated into partial dislocations with formation of stacking faults, the special grain boundaries, the boundaries of incoherent twins and inclusions can serve as places of nucleation of martensitic crystals (of defects of crystal structure). Nucleation at these defects for the case of f.c.c. $\rightarrow$ b.c.c. and other martensitic transformation types (b.c.c. $\rightarrow$ f.c.c., b.c.c. $\rightarrow$ h.c.p.) was considered in [9]. The mechanism of formation of martensitic nuclei in the case of these transitions is more complicated. Using proposed in [10] hard sphere model for describing lattice deformation taking place during MT the mechanism of appearing martensitic nucleus from defect authors [9] presented next manner. Formation of martensitic nucleus proceeds by two shears. At first (twinning) shear by the value $a_{\text {f.c.c. }}\langle 112\rangle / 6$, some intermediate state arises from f.c.c. structure with the structure similar to b.c.c. This proceeds in the result of appearing some dilatation component $a_{\text {f.c.c. }}\langle 112\rangle / 18$ perpendicular to shear plane that brings to enlarging by $5.4 \%$. In this state, sequence of planes does not correspond to terminal b.c.c. structure. To obtain this structure, it is needed second shear by $a_{\text {f.c.c. }}\langle 112\rangle / 16$ corresponding to shear in b.c.c. structure by $a_{\text {b.c.c. }}\langle\mathbf{1 1 0}\rangle / 8$ on each plane and dilatation perpendicular shear plane by $3.6 \%$. As dilatation proceeds during these two shears, they 
can be imaged as invariant plane deformations. The first shear by mechanism of f.c.c. $\rightarrow$ b.c.c. transition [10] can be obtained by means of using group of Shockley partial dislocations arranged at each third close-packed plane. The second shear from this scheme needs to be changed. During the second shear, it is necessary to reconstruct atom configurations obtained in the first shear to b.c.c. structure without rotation initial shear plane.

Scheme of f.c.c. $\rightarrow$ b.c.c. reconstruction and sequence of shears in proposed scheme are presented in (Fig. 1). There is screw dislocation $a_{\text {f.c.c. }}[1 \overline{1} 0] / 2$ situated perpendicular plane $(111)_{\text {f.c.c. }}$. At the first shear, dissociation of this dislocation takes place and then three partial dislocations $a_{\text {f.c.c. }}[1 \overline{2} 1] / 18$ and three partial dislocations $a_{\text {f.c.c. }}[2 \overline{1} \overline{1}] / 18$ arise as a result of transfer over three planes (Fig. 1, $b$ ). Defect thickening takes place during following dissociation of dislocation $a_{\text {f.c.c. }}[1 \overline{1} 0] / 2$ and moving of arising partial dislocations. In further reconstruction (second shear in plane $(11 \overline{1})_{\text {f.c.c. }}=$ $\left.(011)_{\text {b.c.c. }}\right)$, atoms occupy the positions corresponding to b.c.c. structure. Then due to relaxation at interphase boundary 'nucleusparent phase', new partial dislocations arise (Fig. 1, c). In the result, semi-coherent b.c.c. nucleus appears. Then in the final stage (Fig. 1, d), nucleus arises with fully relaxed long-range deformation fields caused by formed partial dislocations. In this (b.c.c.) state,

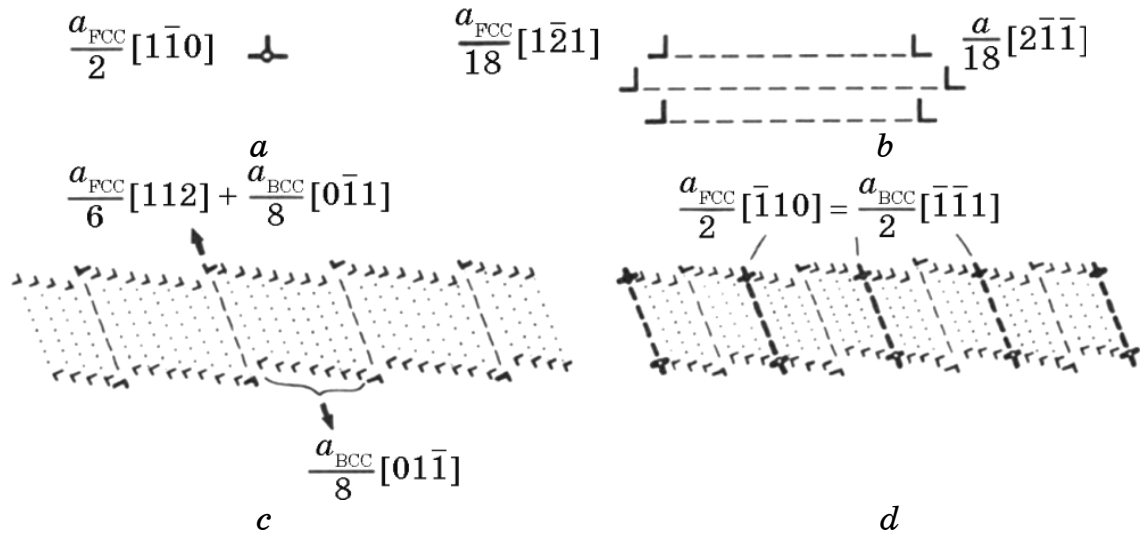

Fig. 1. Scheme of semi-coherent b.c.c. nucleus formation from screw dislocation in f.c.c. structure [9]: $a$-screw dislocation $a_{\text {f.c.c. }}[1 \overline{1} 0] / 2$ in the initial f.c.c. structure; $b$-splitting of dislocation with formation of defect and intermediate structure (on classification [10]); $c$-reconstruction of defect to b.c.c. structure with formation of new partial dislocations on an interphase boundary; $d$-imperfect structure arisen up during formation in b.c.c. phase of new screw dislocations stipulating for relaxation of the long-range deformation fields caused by appearance of partial dislocations arisen on the stage $(c)$. 
nucleus has the Kurdyumov-Sacks orientation relationship with

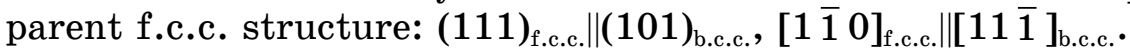

For spontaneous nucleation, it is needed to fulfil following conditions: under increasing of nucleus thickness its energy decreases and becomes equal nil or becomes negative in the case of dissociation of defect of definite size. This condition is fulfilled not always, not to the whole cases of MT. Based on using of experimental values of $E^{\text {def }}$ and $\Delta G^{\text {chem }}$ for $\mathrm{Fe}-30$ wt. $\% \mathrm{Ni}$ alloy, evaluations of the defect thickness, from which martensitic nucleus forms, give thickness of $n^{*}=13$ closepacked planes. This is critical size of defect, which is necessary for appearance of nucleus that consists of 4-5 properly situated dislocations. Thus, defects from which martensitic nucleus arises during f.c.c. $\rightarrow$ h.c.p. and f.c.c. $\rightarrow$ b.c.c. transitions are practically identical. Depending on invariant lattice deformation taking place in initial stages of transformation, martensitic crystals in the Fe alloys arise with habit plane $(111)_{\text {f.c.c. }},(225)_{\text {f.c.c. }}$ or $(31015)_{\text {f.c.c. }}$.

It is proposed to consider formation of martensitic nucleus in b.c.c. $\rightarrow$ f.c.c. transition as dislocation dissociation process, which takes place in reverse direction relatively to f.c.c. $\rightarrow$ b.c.c. transition [9]. Dislocation $a_{\text {b.c.c. }}[1 \overline{1} 1] / 2$ arranged in the $(011)_{\text {b.c.c. }}$ plane can dissociate into partials by next scheme:

$$
a_{\text {b.c.c. }}[1 \overline{1} 1] / 2 \rightarrow a_{\text {b.c.c. }}[0 \overline{1} 1] / 8+a_{\text {b.c.c. }}[2 \overline{1} 1] / 4+a_{\text {b.c.c. }}[0 \overline{1} 1] / 8 .
$$

Under dissociation of groups of these dislocations, the first shear (homogeneous) is accomplish using partial dislocation $a_{\text {b.c.c. }}[0 \overline{1} 1] / 8$. The second shear by value $a_{\text {f.c.c. }}[\overline{1} 2 \overline{1}] / 18$ takes place in plane $(101)_{\text {b.c.c. }}$ becoming $(111)_{\text {f.c.c. }}$. In addition, for obtaining final f.c.c. structure, it is needed definite dilatation. In the result of relaxation of long-range deformation fields, semi-coherent f.c.c. nucleus arises with the interphase boundary structure similar to boundary structure of b.c.c. nucleus like that in (Fig. 1, $d$ ).

Experimental results of the investigations of MT in different alloys testify that b.c.c. $\rightarrow$ f.c.c. transition proceeds very seldom. Indeed, from b.c.c. state, the $9 R$-structures arise more often. These structures with some approach can image as distorted f.c.c. structures having stacking faults in each third planes $(111)_{\text {f.c.c. }}$ (see, for example, martensitic transitions in $\mathrm{Cu}-\mathrm{Al}$ and $\mathrm{Cu}-\mathrm{Zn}$ alloys).

In the case of b.c.c. $\rightarrow$ h.c.p. transitions, which take place in $\mathrm{Ti}$ alloy or in a number of noble-based alloys, for nucleation martensitic mechanism, it can use previously considered mechanism for b.c.c. $\rightarrow$ f.c.c. transition. Partial dislocation $a_{\text {b.c.c. }}[2 \overline{1} 1] / 4$ (this dislocation corresponds to partial dislocation Shockley in f.c.c. structure $\left.a_{\text {f.c.c. }}[112] / 6\right)$ arisen during dissociation of dislocation $a_{\text {b.c.c. }}[1 \overline{1} 1] / 2$ under moving across f.c.c. nucleus transfer it to h.c.p. structure. 
Thus during b.c.c. $\rightarrow$ h.c.p. transition, f.c.c. structure can consider as intermediate structure. In new h.c.p. structure, stacking fault plane is basal plane.

Under consideration f.c.c. $\rightarrow$ f.c.t. transition, mechanism of arising of martensitic nucleus presented before can use if a minor tetragonal distortions in f.c.c. structure account [9]. In this case lattice deformation takes place not in close-packed planes but in the planes of $\{110\}_{\text {f.c.c. }}$ where dissociating defect situated.

Other types of martensitic transitions (transformation with formation of the orthorhombic or tetragonal crystal structures) can be obtained from considered higher if to introduce additional small distortions in the structure of the arising phase. These distortions appear in the result of ordering in the parent phase (long-range, short-range order), anisotropy, and presence of insertion atoms of other type or other reasons. As pointed, higher martensitic nuclei can arise not only at individual dislocations and their groups but also at sections of definite type of grain boundaries, some inclination boundaries, non-coherent twin boundaries, boundaries of particles (inclusions). At these boundaries, definite dislocation groups with non-relaxed stress are present always or these boundaries, their separate sections can image as such dislocation groups. It is important so as the energy of these 'defects' did not increase the total energy of nucleus. Definite confirmation of nucleation and growth of martensitic crystals at these defects (boundaries, subboundaries in $\mathrm{Au}-\mathrm{Cd}$ alloy and twin boundaries in $\mathrm{Fe}-32.3$ wt.\% $\mathrm{Ni}$ alloy) can find in $[11,12]$.

Conditions of growth of nucleus situated in defect plane are also considered in Ref. [9]. Defect becomes instable in respect to nucleus formation if energy of defect is

$$
\gamma=-n \tau_{0}|\mathbf{b}|,
$$

where $n$-number of dislocations with Burgers vector $\mathbf{b}$ forming of nucleus, $\tau_{0}$ - stresses that move dislocations.

Evaluations gave possibility to determine the size of defect forming b.c.c. nucleus of critical size. In $\mathrm{Fe}-30$ wt.\% $\mathrm{Ni}$, during spontaneous formation of nucleus at temperature $M_{\mathrm{s}}$, number of dislocations in defect is $n=16$.

Growth of martensitic nucleus proceeds in the plane of defect arrangement and thickening-perpendicular to the plane of defect. Thickening takes place in the result of appearing of new transformation dislocations the same type that forming initial defect. Again, appeared dislocations have long-range deformation fields as its function consists in change of form that takes place during transformation. 
Calculations of energy change during these processes bring about to conclusion that at nucleus growth continuous increase of dislocation line must play principal role but not formation of new dislocation loops that provides the lattice deformation during transformation as thermal activation of new loops is more difficult. Process of thickening can take place by pole mechanism as in (Fig. 2). This mechanism based on interaction transformation dislocations situated as a rule in a plane of close packing and dislocations of 'forest' that are always present in alloy. Dislocation of 'forest' has Burgers vector with screw component perpendicular plane of defect and it value is equal one interplanar distance. This dislocation will be act as pole dislocation during spiral motion of transformation a dislocation across successive close-packed planes and brings to thickening of nucleus. The process of thickening can be shortly described by the following way (see Fig. 2). Under crossing transformation dislo-

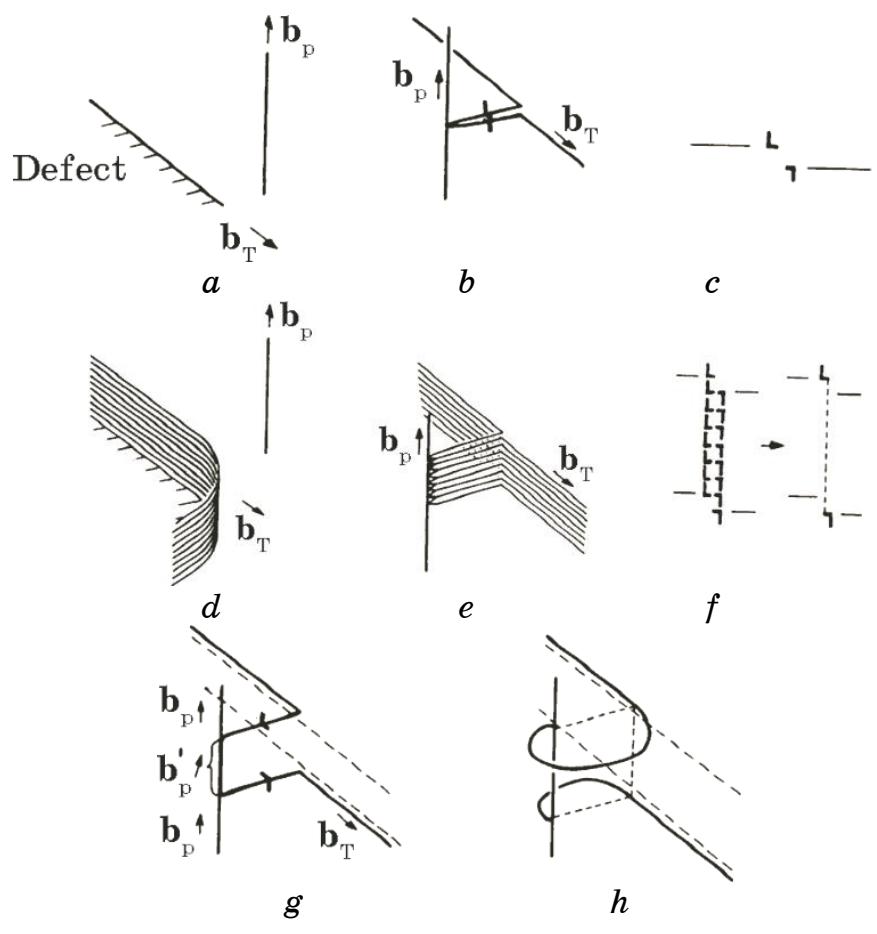

Fig. 2. Thickening of nucleus by pole mechanism [9]: $a$-dislocation of transformation $\mathbf{b}_{\mathrm{T}}$ and pole dislocation $\mathbf{b}_{\mathrm{p}} ; b$-interaction (crossing) of dislocations $\mathbf{b}_{\mathrm{T}}$ and $\mathbf{b}_{\mathrm{p}} ; c$-formation of dislocation dipole; $d$-group of transformation dislocations limiting nucleus; $e$-crossing (interaction) of transformation dislocations and pole dislocation and formation of dislocation dipole; $f-$ interaction of dislocation dipole; $g$-formation of single dipole; $h$-rotation of dislocation dipole round pole dislocation stipulating nucleus thickening. 
cation $b_{\mathrm{T}}$ (equal to $a_{\text {f.c.c. }}[1 \overline{2} 1] / 18$ ) and pole dislocation $\mathbf{b}_{\mathrm{p}}$ (equal to $a_{\text {f.c.c. }}[\overline{1} 01] / 2$ (Fig. 2, $a$ ), threshold arises at transformation dislocation (Fig. 2, $b$ ). During motion, the dipole of partial dislocations reserves for itself (Fig. 2,c). The whole multitude of transformation dislocations at the nucleus front of critical size (Fig. 2, d) at its motion intersects pole dislocation (Fig. 2, $e$ ) and forms dipole at each plane. In the result of their interaction (Fig. 2, $f$ ), single dislocation dipole arises connected to pole dislocation with the distance between its dislocations equal to nucleus thickness. Under influence of Bain deformation, pole dislocation transfers in dislocation with Burgers vector $\mathbf{b}_{\mathrm{p}}^{\prime}$ within nucleus (Fig. 2, g). Transformation dislocations rotate around pole dislocation (Fig. $2, h$ ). During each evolution, close-packed plane moves and nucleus thickens.

In the case of f.c.c. $\rightarrow$ h.c.p. transition, the motion of transformation dislocation $\left.a_{\text {f.c.c. }} .112\right\rangle / 6$ at every second close-packed plane needs for thickening of nucleus. At this transition, the dipole (Fig. $2, g$ ) begins to rotate only after its intersection with two inclination lattice dislocations and arising so named 'twofold pole'.

For heterogeneous nucleation, the dislocation model of martensitic nucleus was proposed in [13, 14]. Authors of model [13] suppose that martensitic nucleus is formed at dislocation line arisen in parent phase (Fig. 3). There is not determined the value of Burgers vector. It is needed for that some single dislocation with arbitrary Burgers vector approximates by plane pile up creating the same stress field. This arbitrariness was needed authors for account real surface energy of nucleus. Authors presented nucleus in the form of

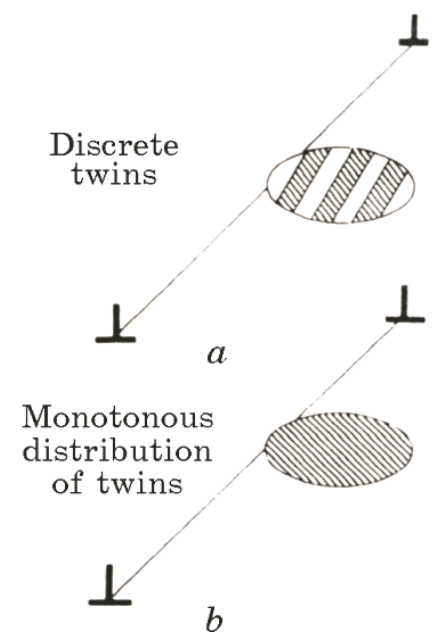

Fig. 3. Scheme of appearance of martensite on dislocation [13]. Nucleus with discrete twins $(a)$. Nucleus with monotonous distribution of twins $(b)$. 
flattened out ellipsoid oriented definite manner. Evaluations of barrier for heterogeneous nucleation at $250 \mathrm{~K}$ in $\mathrm{Fe}-29$ wt. $\% \mathrm{Ni}$ with number dislocation in pile up equal 1 and surface energy $23 \mathrm{erg} / \mathrm{cm}^{2}$ showed that ratio of ellipsoid axes for minimal nucleus is less than 8. In the case of critical nucleus with amount of atoms near 1000, ratio of ellipsoid axes is equal to 20. For realistic surface energy $200 \mathrm{erg} / \mathrm{cm}^{2}$, number of dislocations needed for appearing of the martensitic nucleus is equal to 10 . Unfortunately, authors propose no mechanism providing following growth of nucleus and formation of macroscopic martensitic crystal.

Formation of the martensitic nuclei during MP in steels is considered in [14]. It is accepted that martensitic nucleus has the form of stretched ellipsoid. Energy change during nucleus formation has appearance:

$$
E_{\text {tot }}=E_{\text {chem }}+E_{\text {def }}+E_{\text {surf }} \text {, }
$$

where $E_{\text {chem }}$-difference of chemical energy of parent and new phase, $E_{\text {def }}$-elastic energy arising in the result of crystal structure discrepancy at interphase boundary, $E_{\text {surf }}$-energy of coherent interphase boundary. After substitutions, they obtained:

$$
E_{\mathrm{tot}}=2 \pi a^{2} \sigma+\frac{16 \pi}{3}(s / 2)^{2} \mu a c^{2}-\Delta f \frac{4 \pi}{3} a^{2} c,
$$

where $\sigma$-surface energy per unit area, $\mu$-shear modulus in austenite, ' $c$ ' and ' $a$ '-semi-thickness and radius of ellipsoid (used $c / a=$ $=0.03), \Delta f$-difference of free energies of parent and martensitic phase per unit volume. As solution, it is appeared that coherent deformation energy (calculated according to Eshelby elasticity theory) is by 25 times greater than chemical free energy change that is critical nucleation barrier is too great for spontaneous formation of martensite (under reasonable choice $E_{\text {chem }}$ ). It is appeared also that energy change is not very sensitive to the ratio $c / a$.

They imaged ellipsoidal nucleus as set of twins of different thickness. Alteration of coherent deformation energy during nucleation formation can be minimized by changing thickness correlation. Thus, consideration of different conditions of formation of martensitic nucleus resulted in conclusion that critical nucleus must be (most probably) thin twinned ellipsoid the orientation of which in austenite is not very much critical if he is located in area of 'minimum energies'.

An energy needed for formation of nucleus, as shown in the performed estimations, is sensible to $\sigma$, to the change of free energy $\Delta F$, and to the amount of shear $s$ (which is parallel to the plane of ellipsoid). The critical sizes of (ellipsoid) nucleus also depend on 
these parameters. The performed estimations result in the followings dependences:

$$
\begin{gathered}
c_{\text {crit }}=\frac{2 \sigma}{\Delta f}, \\
a_{\text {crit }}=\frac{16 \sigma \mu(s / 2)^{2}}{(\Delta f)^{2}} .
\end{gathered}
$$

These equations are suitable only partly for the case of twinned nucleus, as at their receipt energy of twin boundaries was not taken into account. However, estimations show that influence of twin boundaries on an energy change not very much substantial. The main influence on energy barrier for formation of nucleus renders superficial energy $\sigma$. So, change $\sigma$ from $20 \mathrm{erg} / \mathrm{sm}^{2}$ to $200 \mathrm{erg} / \mathrm{sm}^{2}$ results in the increase of $E_{\text {min }}$ from $14 \mathrm{eV}$ to $1.4 \cdot 10^{4} \mathrm{eV}$. Authors supposed that nucleation on defects in austenite can substantially decrease energy barrier to formation of nucleus because of interaction of the deformation field of defect (dislocation) with the deformation field of embryo. Therefore, in expression for energy change (8), they added additional term $E_{\text {inter }}$. Authors suggest examining a nucleation on a dislocation loop for Poisson ratio $v=1 / 3$

$$
E_{\text {inter }}=-2 \mu s \pi a b c .
$$

The carried out estimations of energy change in the case of nucleation of martensite on defects (the dislocation loop) show that in this case formation of martensitic nucleus takes place spontaneously, but nucleus must be twinned for it subsequent growth. For appearance of nucleus, some special orientations of dislocations or their specific configurations are not needed. They are not structural part of embryo. Authors give them a certain catalytic role. It is marked that for further growth (thickening) of nucleus the participation of dislocations is not obligatory. The role of twinning of nucleus consists of lowering of his general energy.

For confirmation of the model, authors [13] allude to the experimental results of electron microscopic researches of MT in the deformed stainless steel of type 18/8 [15]. In this work, at a direct supervision of processes of MT in the electron microscope, they did find out the formation of the plates of $\alpha$-phases on crossing of two strips of gliding at passing of the dislocation pile up. However, in the work, only formation of already macroscopic (formed) plates of $\alpha$-phase is given. Experimental evidences of existence of the real martensitic nuclei or observations of the processes of the nucleus formation of the new phase did not obtain. At crossing of two strips of gliding, there are martensitic formations as long ellipsoids, 
which give reflexes of b.c.c. $\alpha$-phase. The size of less semi-axis of ellipsoid is equal to a few ten of angstrom. The authors of work named such formations as 'elementary (?) martensite'. At further growth, ellipsoids take shape of polyhedrons with a habitus $(\overline{5} 2 \overline{9})_{\gamma}$. Is it necessary to point out that martensitic crystals, arising up in massive specimens, have a habitus $\{225\}_{\gamma}$ or $\{112\}_{\gamma}$ ? Calculations carried out in the work allowed estimating the number of dislocations in a pile up, caused the formation of martensitic plate. As appeared, the amount of dislocations in such pile up is equal to 22 .

Using supposition about the thermally activated motion of dislocations during formation of martensitic nucleus, as made in Ref. [9], and equation determining activation energy for such nucleation:

$$
\Delta W_{\mathrm{a}}^{\text {subtr }}=Q_{0}+\left(\tau_{\mathrm{a}}+\frac{\rho E}{|\mathbf{b}|}+\frac{2 \sigma}{n|\mathbf{b}|}\right) V^{*}+\frac{\rho V^{*}}{|\mathbf{b}|} \Delta G,
$$

where $Q_{0}$ is activation energy of moving of dislocation in absence of driving force, $\tau_{\mathrm{a}}$-is athermal stress, causing the motion of dislocation, $\rho$-is density of atoms on close-packed plane, $\mathbf{b}-$ Burgers vector of partial dislocation, which for f.c.c. $\rightarrow$ b.c.c. transformation is equal: $a\langle 112\rangle / 18, E$-energy of coherent deformation, $\sigma$-surface energy of interphase 'austenite-martensite' boundary, $n$-number of atomic planes in nucleus, $\Delta G$-change of chemical free energy per mole, $V^{*}$-activating volume for motion of dislocation, in Ref. [16] activation energy calculated at certain parameters $(n=16)$ and got values were compared to experimental one. As appeared with the chosen parameters, the calculated and experimental values of activation energy are enough well coincide in the wide interval of temperatures (from $77 \mathrm{~K}$ to $203 \mathrm{~K}$ ). In opinion of authors [16], these results confirm applicability offered in [9] model for the analysis of processes of nucleation during martensitic transformation.

\subsection{Experimental Confirmation of Presence of Martensitic Nuclei}

Attempts to observe and identify martensitic embryos in different materials (alloys based on iron, non-ferrous alloys) were undertaken as early as 60 th of past century [17, 18]. Their search began to be conducted especially actively with development of methods of electron microscopy, which allows to find out different imperfect structures, set of type of the defects, their location, very small areas of other phase. However, the electron-microscopy studies carried out with many materials and obtained experimental results did not give reliable confirmation of existence of martensitic nuclei. A question remains opened: what one has to consider as martensitic nucleus? Found out microstructure features in parent phase in the alloys of 
$\mathrm{Fe}-\mathrm{Ni}$ from 30 and 32.3 wt.\% $\mathrm{Ni}[17,18]$ at temperatures near $M_{\mathrm{s}}$ are well enough possible to explain by appearance of very little (thin) martensitic plates with the stretched dislocations or their well-organized clusters [18] or by formation of twins in the martensite which at certain sections (orientations) can be accepted as martensitic nucleus.

Electron-microscopy investigations in situ (directly in an electron microscope) on the search of martensitic nuclei in the thin-films of alloy of $\mathrm{Fe}-27.6 \% \mathrm{Ni}-0.08 \% \mathrm{~V}-0.05 \% \mathrm{C}$ (wt.\%) prepared from the specimens preliminary deformed and then cooled to the necessary temperature were conducted in Ref. [19]. Authors came to conclusion that found out near the martensitic crystals dislocation formations of type of 'butterfly' are martensitic nuclei. Such formations result in appearance of interference bands on electron microscopy images. However, the same interference image may arise up in the result of presence in the sample of martensitic lamina inclined to the surface of foil. A like microstructure images that is appearance of interference bands ahead of growing martensitic crystal in the alloy of $\mathrm{Cu}-\mathrm{Al}-\mathrm{Ni}$ observed in Ref. [20]. Interference bands are well explained by the origin of moiré because of imposition of two crystals: thin martensitic plate inclined to the surface of foil and area of parent phase. At some orientations, distinction in the interplanar distances of parent and martensitic phases are insignificant that results in appearance of moiré contrast before growing martensitic crystal. Diffraction reflexes from such martensitic plate get hardly because of small volume of this plate.

Authors of Ref. [19] revealed that, during small deformation, long dislocation loops appear at first and then along some of them dislocation clusters appear. The nuclei of martensite from which at the subsequent cooling or deformation in an electron microscope thin martensitic plates grow with high-density dislocations as a substructure appear on such groups of defects. A large martensitic plate consists of group of such thin plates. The performed calculation of diffraction pictures from areas with 'nucleus' brought authors over to the conclusion that crystalline structure of 'nuclei' is intermediate between parent (f.c.c.) and martensitic (b.c.c.) structures, has an orthorhombic lattice with parameters: $a=0.251 \mathrm{~nm}$, $b=0.410 \mathrm{~nm}, c=0.435 \mathrm{~nm}$ and angles: $\alpha=\beta=\gamma=90^{\circ}$. What does 'intermediate' structure mean, for what it is needed, which is its role in the proceeding of MT, and how it appears, authors did not explain. This work presumably is unique, in which arising of some 'intermediate' phase (structures) during direct MT is reported. In accordance with scheme suggested in [19], during martensitic transition, there is a shear $[\overline{2} \overline{1}]_{\text {f.c.c. }} / 6$ between three close-packed planes but not two as in the case of formation of stacking fault. In 
case of formation of martensitic phase, shears in neighbouring nuclei take place in opposite directions.

Problems of nucleation of martensite and formation of nuclei of martensitic $\alpha$-phase on crossings of micro shear bands, arising up in the process of deformation in stainless steel 304 considered in [21]. In electron-microscopy investigations of the deformed samples, they did find out areas, which on dark field images in reflexes of $\alpha$ phase have the appearance of thin bands 5-7 nm in thick. The authors of work consider them as the martensitic nuclei. Accordingly to the conducted estimations, the stable nucleus of martensite consists of 27 close-packed planes (type $\{111\}_{\text {f.c.c. }}$ ), that corresponds his thickness of $5.7 \mathrm{~nm}$.

Based on the obtained experimental results, authors [21] came to conclusion that martensitic nuclei arising up at different degrees and types of deformation in the initial state have an identical base structure: microstructure, geometry and crystallographic peculiarities. It is important that, during the deformation, there were the special great numbers of defects, located in planes $\{111\}$ at the shear of $a\langle 112\rangle / 6$. On crossings of such defects, for example, microshear bands, stable elements appear with b.c.c. structure. The process of formation of the special defects and formation of martensitic nucleus is schematically presented in Fig. 4. At creation of scheme of reconstruction of f.c.c. structure into b.c.c. structure, authors used supposition about two invariant plane deformations (shears) from a model offered in [10]. Except for these two shears, for the receipt of necessary structure, some dilatation is needed. However, for formation of semi-coherent interphase boundary be-

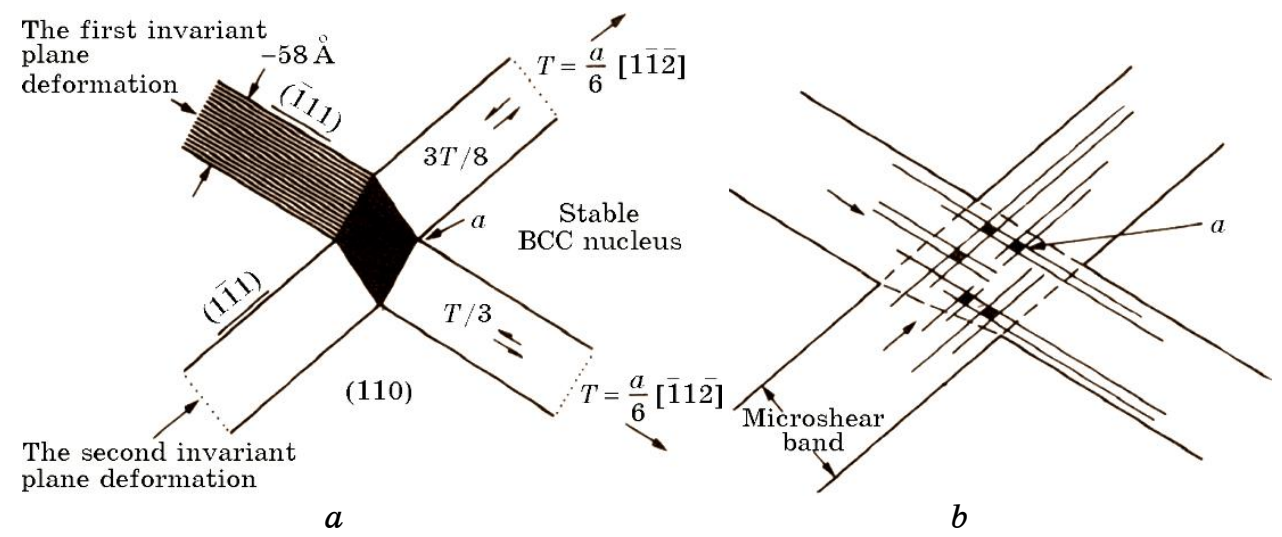

Fig. 4. Scheme of formation of specific defect at which a martensitic nucleus arise [21]: $a$-crossing of defects and formation of stable nucleus of martensite; $b$-irregular location (formation) of martensitic nucleus in a wide micro shear band or at crossing twin defects. 
tween the arising b.c.c. structure and the parent f.c.c. matrix, more complicated invariant deformations of crystalline structure (lattice) are required.

The analysis of electron microscopy images obtained in [21] allows to conclude that there are the lens form plates of martensite (b.c.c. $\alpha$-phase) but not nuclei are visible. They have a size near 1 $\mu \mathrm{m}$ (see [21]) and the reflexes of martensitic phase are present on diffractograms from areas with these plates. On dark field images obtained in the reflexes of $\alpha$-phase, these plates are visible ('shine'). Therefore, in any way they are impossible to consider as nuclei: on the presented microstructures are there, they formed crystals of martensite, which give the diffraction picture of $\alpha$-phase. Interesting model of the formation of martensite in almost equiatomic alloy of $\mathrm{Ti}-50.3$ at.\% $\mathrm{Ni}$ is offered in Ref. [22]. At approaching to the temperature of beginning of MT because of appearance of deformation inhomogeneities there are distortions in the planes $\{110\}_{B 2}$. They are consequence of dynamic displacements of atoms of $\mathrm{Ti}$ and $\mathrm{Ni}$ in the alternating planes $\{\mathbf{1 1 0}\}_{B 2}$ in the direction of $\langle\mathbf{1 1 0}\rangle_{B 2}$. The strongly diffused diffraction reflexes appear on the diffraction pictures of B2-phase. Displacements of atoms of $\mathrm{Ti}$ and $\mathrm{Ni}$ result in the formation of domains as very thin plates with the habitus $\{110\}_{B 2}$. It is assumed that the structure of these domains oscillates between the structures of high temperature and low temperature phases. At decreasing in a temperature below than beginning of MT from such domains, martensitic crystals grow.

Consideration of martensitic f.c.c. $\rightarrow$ b.c.c. transformation in elastically anisotropic crystals at a heterogeneous nucleation on dislocations resulted in a conclusion that a nucleus of new phase is not one domain particle as it was usually accepted but compound selforganized ensemble consisting of twin connected micro domains [23]. Metastable martensitic nuclei on dislocation loops appear higher than temperature of beginning of martensitic transformation. A twinning in a martensitic nucleus provides the decreasing of total level of tensions because of accommodation of twinconnected microdomains.

From estimations obtained on the basis of experimental investigations of the martensitic transformation in small particles, the number of originally existent places of origin of martensite makes from $10^{5}$ to $10^{7}$ on $1 \mathrm{~cm}^{3}$ [24].

Using the method of impulsive loading, the time of origin at athermal MT in the alloys of $\mathrm{Fe}-\mathrm{Ni}(-\mathrm{C})$ with the temperature of beginning of martensitic transformation $M_{\mathrm{s}}<240^{\circ} \mathrm{C}$ was estimated [25]. This time in preliminary deformed due to passing of shock wave across the material makes less than 55 nanoseconds.

Simultaneously with the problem of the formation of martensitic 
nucleus, there is a problem of the state and structure of interphase boundaries. At the initial stages, such boundaries apparently must be coherent or partly coherent even in alloys with not thermoelastic MT for decreasing of arising stress and facilitation of moving of the interphase boundary. At the subsequent increase of nucleus and formation of martensitic crystal, the coherences is violated, on boundaries and in a crystal, dislocations appear. Formation problems, structure and state of interphase boundaries of crystals of martensite in alloys with different character of martensitic transition are considered in detail in Ref. [26].

Numerous attempts to observe experimentally the defect structure of places of nucleation of the martensitic crystals in different alloys both at cooling and at MT under influence of the applied stress were undertaken. We already reported about not very successful and reliable attempts to discover nuclei of martensitic phase $[11,12]$. By the use of methods of high-resolution electron microscopy, the formation of martensitic nucleus with orientation relationship with the parent phase of type of Kurdyumov-Sachs and orientation of habitus $(\mathbf{1 1 1})_{\text {f.c.c. }} \|(\mathbf{0 1 1})_{\text {b.c.c. }}$ was set in the alloys $\mathrm{Fe}-$ $23 \% \mathrm{Ni}-3.8 \% \mathrm{Mn}$ and $\mathrm{Fe}-9 \% \mathrm{Cr}-1.1 \% \mathrm{C}$ (wt. \%) [27]. Growth of nucleus took place in the direction of $[101]_{\text {f.c.c. }}||[111]_{\text {b.c.c. }}$. The study of crystalline structure allowed establishing its change from f.c.c. to b.c.c. at transferring to central part of embryo. However, by the conclusion of authors, transition to b.c.c. structure is not completed in central part of nucleus. Generally, it is not clear because a crystalline structure for these alloys can be or f.c.c. (in a parent phase) or b.c.c. (in a martensitic phase). Authors do not explain an intermediate structure between f.c.c. and b.c.c. crystalline structure.

The obtained results testify about complication of problem. There is not reliable determination what to consider as martensitic nucleus. What size and structure martensitic nucleus has? From what size, it is already the martensitic crystal? The second question is easier. Apparently, minimum nucleus having definite morphology of new-phase crystal structure, giving corresponding diffraction pattern, is already a martensitic crystal. However, questions remain, and new reliable experimental results and proper theoretical calculations and models are needed.

A set of interesting and important results relating to the processes of origin of the martensitic phase and growth of the martensitic crystals was obtained at use of the methods of electron microscopy. The origin of martensitic $\gamma^{\prime}$ - and $\beta^{\prime}$-phases on dislocations under influence of the stress put to the thin films of the $\mathrm{Cu}-\mathrm{Al}-\mathrm{Ni}$ alloys directly in an electron microscope is reported in Ref. [28]. Investigation of processes $\mathrm{MT}$ in the $\mathrm{Cu}-\mathrm{Al}-\mathrm{Ni}$ alloys showed that growth of martensitic crystals began from particles $\gamma_{2}$-phase or near-by 
them, that is in those places where the concentration of $\mathrm{Al}$ in parent phase became lower [29]. It related to that on formation of the enriched by aluminium $\gamma_{2}$-particles $\mathrm{Al}$ concentration in the areas of parent phase nearby particles decreases and the temperature of beginning of MT becomes higher.

During the electron microscopy study of MT in thin films of $\mathrm{Cu}-$ $14.1 \% \mathrm{Al}-5.0 \% \mathrm{Ni}(\mathrm{wt} . \%$ ) alloy, some special places of nucleation of martensitic crystals ( $\gamma^{\prime}$-phase) have not been found. Under influence of arising local stress, thin (a few $\mu \mathrm{m}$ ) martensitic plates begin to grow from the edge of hole or appear in the areas of foil free of defects-dislocations or their clusters, in any case, at this orientation of thin film [20]. New crystals appear nearby from before arising up. Sometimes, ahead of growing crystal moving of plane clusters of dislocations is observed. In these areas, as microdiffraction studies showed, no changes of crystalline structure yet take place, a parent phase is preserved.

By the method of low-energy electron diffraction highly sensitive to the structural peculiarities on the surface attempts to discover the 'frozen' embryos of new phase in the single crystals of cobalt at both the direct MT and the reverse one were undertaken [30, 31]. These attempts appeared unsuccessfully. It was observed no preferable places of nucleation with the structure of arising at a change of temperature new phase. On that ground, the authors of these works deny the special role of surface in the nucleation of new phase and in the processes of martensitic transformation. However, numerous experimental researches of processes of MT show that the first crystals of martensite arise up at first on the surface.

\section{MARTENSITIC TRANSFORMATION IN THE SUBJECTS OF SMALL DIMENSIONS}

All subjects of small dimensions, in which the peculiarities of martensitic transformation will be considered, can be divided into the followings basic groups: separate particles of different size and inclusions in massive materials, powder-like materials, thin-films (obtained by thinning, high-rate quenching from the liquid state, deposition), nanocrystals, and nanomaterials.

\subsection{Martensitic Transformation in Particles and Inclusions}

Martensitic transformation in particles and inclusions takes place with some peculiarities conditioned by their dimensions. In particular, linear defects (dislocations) can absent in such objects and a number of existing up to transformation and again arising nuclei of 
new phase can be restricted in connection with small size of the particles.

Investigation of peculiarities of martensitic transformation in monocrystalline spheroid particles of the size $0.1-0.3 \mathrm{~mm}$ in $\mathrm{Fe}-$ (25.7-30.6) wt.\% Ni alloys showed that during cooling martensite does not arise in the monocrystalline state [32]. Transformation takes place mainly as 'explosion' with formation of plenty of the martensitic needles. However, transition interval stretches on the wide area of temperatures. For example, in the $\mathrm{Fe}-30.6$ wt. $\% \mathrm{Ni}$ alloy, transformation begins at $-12^{\circ} \mathrm{C}$ and finished below $-196^{\circ} \mathrm{C}$. A 'surface' martensite arises only during the concentration of nickel less than 30.6 wt.\%. Martensitic phase appears as thin needles considerably less in size as compared to arising in bulky singlecrystalline specimens. Degree of $\gamma \rightarrow \alpha$-transformations (volume of martensitic phase) is substantially higher than in massive specimens: an amount of not transforming parent phase after compression deformation is $\mathbf{1 - 5} \%$ only.

In the single crystal, the zero-defect particles of $\mathrm{Cu}-1.5$ wt. $\% \mathrm{Fe}$ alloys containing $0-5$ wt.\% of $\mathrm{Ni}$, the degree of MT depends on nickel content in particles [33]. Particles of the diameter 0.002-0.2 $\mu \mathrm{m}$ are obtained by extracting at the electropolishing of specimens of these alloys after their thermomechanical treatment and additional annealing at $700^{\circ} \mathrm{C}$. In the extracted particles, content of nickel could attain 10-20 wt. $\%$, but only at 5\% of its initial concentration in an alloy. Electron microscopy investigations showed that, at low nickel concentration, MT in the extracted particles takes place completely and, as a result, from single-crystalline $\gamma$ phases, twinned single crystalline $\alpha$-phase is formed. The minimum volume of martensite contains, on estimations, 5000 atoms. At the increase of nickel concentration, there is the partial or complete stabilizing of parent phase in particles. Martensitic transformation in particles, containing $\mathrm{Ni}$, begins on the surface: needles (plates) appear by the width of $3 \mathrm{~nm}$. In partly transformed particles at the further cooling, MT does not take place. As it was not found out defects (dislocations) in the extracted particles, a conclusion is as follows: in process preceding the MT in such particles, there is not a necessity for defects. The nucleation of martensitic crystals in these particles takes place not on defects.

Martensitic transformation in the particles of $\mathrm{Fe}_{\gamma}$ located in $\mathrm{Cu}$ matrix does takes place with some peculiarities as compared to transformation in the extracted particles of $\mathrm{Fe}_{\gamma}$. Under investigation of MT in the monocrystalline alloy of $\mathrm{Cu}-1.0$ wt.\% Fe, it was shown that, during deformation directly in an electron microscope, there is interaction of gliding dislocations with the $\mathrm{Fe}_{\gamma}$-particles [34]. The MT begins only in the case of interaction of the primary 


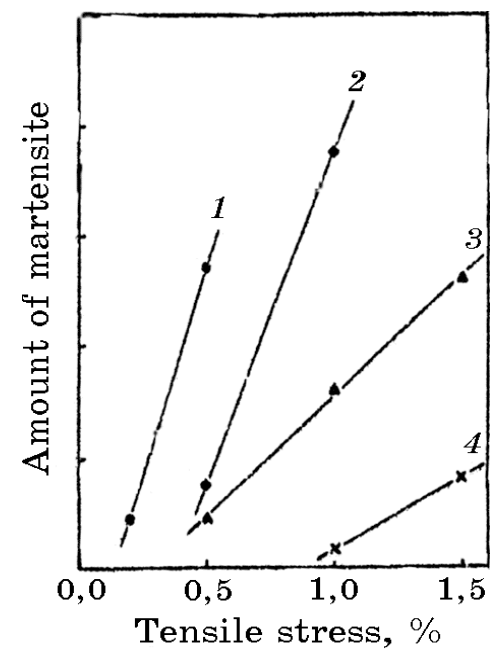

Fig. 5. Dependence of amount of martensite in the particles of different sizes on the size of tensile stress [34]; $1-130 \mathrm{~nm}, 2-70 \mathrm{~nm}, 3-50 \mathrm{~nm}, 4-30 \mathrm{~nm}$.

and secondary systems of gliding with a particle. The crystals of martensite appear during $0.02 \mathrm{~s}$ after the beginning of growth. Around particles, there are plenty of dislocations. Their appearance, in opinion of authors, is conditioned by shear deformation at MT. Amount of appearing martensite is determined by the size of particles and degree of deformation. It was shown that with the increase of size of particles the degree of transformation (volume of martensite) grows. Figure 5 presents the dependences of amount of martensite $\left(\mathrm{Fe}_{\alpha}\right)$ on the amount of the applied tensile stress.

Influence of size of particles on proceeding of MT was observed in [35]. In this work, it was shown that in obtained by the method of gas evaporation particles with a size 10-200 nm at a room temperature the initial f.c.c. structure is saved, although in the massive state at $20^{\circ} \mathrm{C}$, the h.c.p. phase exists. In particles, there are one or two systems of twins on the planes $\{111\}_{\text {f.c.c. }}$. In a number of cases, plane defects (presumably stacking faults) found out; possibly, they arose up because of proceeding of MT. However, in particles, dislocations are not found out. A conclusion is as follows: in process, MT in such particles takes place without the stage of nucleation, i.e., the nuclei of martensite is absent.

The size of particles influences also on the crystallography peculiarities of MT. So, in the alloy of $\mathrm{Cu}-1.0 \mathrm{wt}$. $\%$ Fe, relationship of Kurdyumov-Sachs between f.c.c. and b.c.c. structures during martensitic transition in spherical particles preserves only at their diameter less than $20 \mathrm{~nm}$ [36]. In particles with size more than $20 \mathrm{~nm}$, deviation from an exact orientation is observed because of rotating of particles 
on angle up to $4.2^{\circ}$ as a result of shear by system of $\{111\}\langle 111\rangle_{\text {f.c.c. }}$ conditioned by the mechanism of MT and slipping in $\mathrm{Cu}$-matrix.

\subsection{Martensitic Transformation in Powder Materials}

The peculiarities of martensitic transformation in powder materials are conditioned by a few reasons: by the sizes of particles (powder) used at a subsequent compaction, conducting of the corresponding deformation and thermal treatment that bring to certain structural changes, which can influence on further phase transitions in these materials.

Investigations of $\alpha \rightarrow \gamma$ - and $\gamma \rightarrow \alpha$-transitions in compacted together with the oxide of aluminium powders of iron of different purity showed that both the size of particles and number of cycles of these transitions influence on the temperatures of these transitions [37]. By decreasing of size of the particles below $70 \mu \mathrm{m}$, temperature of the first $\alpha \rightarrow \gamma$-transition rises (Fig. 6, $a$ ) substantially regardless of purity of initial powder of iron. The size of particles influences lesser on $\gamma \rightarrow \alpha$-transition temperature which lowering by decreasing of radius of $\mathrm{Fe}$ particles. At the second cycle, transformation temperature increases for all sizes of particles (upper curve in Fig. 6, $a$ ) and $\gamma \rightarrow \alpha$ transition decreases a little (lower curve in
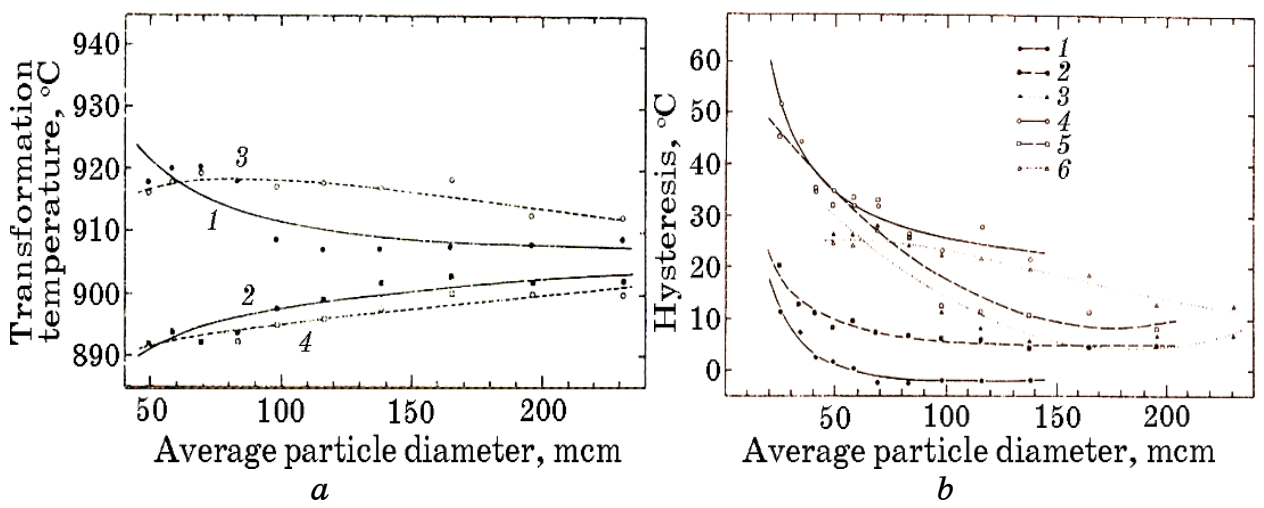

Fig. 6. $a$-dependences of temperatures of the $\alpha \rightarrow \gamma$ and $\gamma \rightarrow \alpha$ transitions on the size of particles at the first and second cycle in pressed Fe-powders [37]. First cycle (curves 1, 2): $\bullet-\alpha \rightarrow \gamma, \mathbf{n}-\gamma \rightarrow \alpha$. Second cycle (curves 3 , 4): $\circ-\alpha \rightarrow \gamma$, $\square-\gamma \rightarrow \alpha$. $b$-dependence of hysteresis value on average diameter of Fe-powders particles [37]. 1-B-214, first cycle; 2-Atomet, first cycle; $3-\mathrm{REP}$, first cycle; $4-B-214$, second cycle; 5 -Atomet, second cycle; 6 -REP, second cycle. Here, $B-214$ is high-purity Fe-powder; Atomet is annealed sponge Fe-powder; REP is Fe-powder with spherical particles. 
Fig. 6, a). The hysteresis value of these transitions increases at decreasing of particle diameter (Fig. $6, b$ ) and number of cycles.

Metallographic studies carried out in Ref. [37] allowed concluding about the influence of grain sizes, triple joints of grains and surface size of grains on the processes of nucleation of new phase. By authors' opinion, nucleation of $\gamma$-phase proceeds on the grains and their joints, especially triple. Into grains, more high energy is required for nucleation. At decreasing of the indicated quantities, the amount of suitable places for nucleation is substantially lowering what results in growth of temperature of $\alpha \rightarrow \gamma$ transition. The increase of temperature of this transition during second cycle is related to the growth of the size of grains because of overheat and more difficult nucleation. Decreasing of $\gamma \rightarrow \alpha$ transition temperature is not explained by authors with microstructure peculiarities but with distinction of the chemical composition of the particles of different sizes. As this distinction is not very much, its influence is insignificant. In addition, this transition takes place by the formation of nuclei and their subsequent growth. Dependence of hysteresis value on the size of particles authors, naturally, also explains by the microstructure peculiarities of the investigated materials: decreasing of grain number at lowering of the size of particles and easier nucleation during $\alpha \rightarrow \gamma$ transition.

The fulfilled analysis of the kinetics of phase transitions in powder-like materials showed that a key parameter determining kinetics is a relation of the transformation time of the whole particle $\tau_{\mathrm{G}}$ to the time $\tau_{\mathrm{N}}$ necessary for formation of nucleus: $\tau_{\mathrm{G}} / \tau_{\mathrm{N}}$ [38]. This relation is in the following dependence on the particle size $L: 1 / L^{4}$. Theory is suitable for a case when relation $\tau_{G} / \tau_{N}$ is small and a few nuclei are present in a particle only. Rate of nucleation is determined by the expression

$$
J(t)=\frac{N}{\tau_{\mathrm{N}}} \exp \left(-t / \tau_{\mathrm{N}}\right),
$$

where $N$ is total amount of crystals in powder. It is assumed that nucleation takes place on defects. Size $\tau_{\mathrm{N}}$ is determined by the following dependence

$$
\tau_{\mathrm{N}}=\left(L_{0} / L\right)^{3} \tau^{\prime},
$$

where $L_{0}$ is average distance between defects and $\tau^{\prime}$ is a measure of nucleation velocity on one defect. Amount $\left(L_{0} / L\right)^{3}$ determines the number of defects in a crystal, which a nucleation is possible on. If $L$ is comparable with $L_{0}$, that is in the case of absence of defects, in the crystal nucleation and, accordingly, phase transition is not impossible. 
Powder materials display the same properties as well as massive. For example, in the alloys of NiTi, got hot pressing of powders of $\mathrm{Ni}$ and $\mathrm{Ti}$ with the homogeneous distribution of pores measuring 50-200 $\mu \mathrm{m}$ the same martensitic transformation takes place as well as in standards got from the cast alloys [39]. In this alloy, a superelasticity conditioned by MT is fully reversed also. At high porosity $(40 \%)$ in the quasi-binary alloy of TiNi-TiPd obtained from powders, martensitic transformation proceeds in wide interval $\left(250^{\circ} \mathrm{C}\right)$ because of large chemical heterogeneity [40]. In the cast alloy of the same composition, this interval is only $30-40^{\circ} \mathrm{C}$.

\subsection{Martensitic Transformation in Thin Films}

There are a few methods of production of thin films, in thick less than $100 \mu \mathrm{m}$. Basic methods are as follow: chemical or electrolytic thinning, evaporation by different methods, rapid quenching from the liquid state. The state of films at the use of these methods can substantially differ as a result of the influence of such factors, as temperature, arising stress, influence of substrate (for example, at evaporation), existing and appearing during production heterogeneities. The degree of influence of these factors is different and determined by the conditions of the film production. We will consider the peculiarities of MT in thin films, got different methods, separately for each case.

Martensitic transformation in the films obtained by thinning. Thinning by a chemical or electrolytic polish is more frequent than all used for preparation of samples for electron microscopy investigations. In this case, the influence of thickness on the peculiarities of MT is conditioned by a few factors: dimensions, more essential influence on the nucleation of martensite of present inhomogeneity, substantial role of surface both in the processes of nucleation of the new phase and during subsequent growth of crystals.

During investigations of MT peculiarities in the thin films of $\mathrm{Cu}-14.1 \% \mathrm{Al}-\mathbf{5 . 0} \% \mathrm{Ni}$ (wt.\%) alloy ( $M_{\mathrm{s}}$ near-by room temperature), it was set directly in an electron microscope that in areas highdensity dislocations a martensitic phase does not appear [20]. It can be related to requirement of the special type of dislocations and their specific configuration for formation of nucleus of martensite. At the same time, some preferable places of nucleation of the martensitic crystals have not been observed. It was shown that under influence of arising up during investigations stress the plate-like crystals of martensite appear in thin films. As a rule, plates grow from the edge of foil. Rate of the plate growth is not high: there was, for example, moving of interphase boundary on $5 \mu \mathrm{m}$ during 5 sec. It should be noted that the substructure of the martensitic 
crystals arises up on the earliest stages of his appearance, simultaneously with their formation and interphase boundaries are flat and straight one. Growth of plate is accompanied by the appearance of stress in parent phase that was set by the formation of dislocation piles up in front of crystal and by moving of this pile up in the process of growth of crystal.

During MT, there is a morphology change of the martensitic crystals in thin films. If, in the massive samples of the alloys with thermoelastic MT during cooling below $M_{\mathrm{n}}$, there are needle-shaped crystals, in thin films (for example, in CuAlNi, TiNi), a martensite appears as thin plates with straight interphase boundaries [20, 41]. Plates grow or decrease during change of temperature or stress state of the film practically without hysteresis. New plates, as a rule, appear near arising first. After disappearance of plates because of reverse MT during repeated cooling, martensitic plates growth in those places, which are at first direct MT. The authors of work [41] observe the change of orientation of habitus with (334) $)_{B 2}$ on $(112)_{B 2}$ at the sizes of plates lesser $10 \mathrm{~nm}$.

The change of structure of interphase boundaries and substructure of martensitic plates during MT in thin films (thickness 30 $\mu \mathrm{m})$ of $\mathrm{Fe}-\mathrm{Ni}-\mathrm{Co}-\mathrm{Ti}$ alloys observed [42]. Interphase boundaries become bent (there are straight boundaries of crystals in the massive specimens). Instead of high density of twins in the plates, there are dislocations and more thin twins. In thinned samples, as authors of the work mark, there is a change of orientation relationship between parent and martensitic phases. If, in the massive specimens, there is nearly Nishiyama relationship, in thin films, in which martensite appears with dislocations, there is $5^{\circ}$ deflection from this orientation.

Martensitic transformation in films obtained by evaporation. In the last decade for the obtaining of thin films, the different methods of evaporations have obtained a wide application; among them, magnetron and thermal depositions are basic. Advantage of these methods is possibility to obtain fully certain thicknesses of the films. There are some failings, mainly, heterogeneity of composition, difficulty of its control, complications with following heat treatment in the case of its necessity. We will consider the basic peculiarities of MT in the films obtained by means of these methods.

Investigations by electron-microscopy methods of the structural and phase states arising up in the films of $\mathrm{Cu}-\mathrm{Al}-\mathrm{Ni}$ and $\mathrm{Cu}-\mathrm{Al}-$ Mn alloys (with $M_{\mathrm{s}}$ below $0^{\circ} \mathrm{C}$ ) obtained with thermal deposition on substrate of different type (copper, aluminium, glass) showed that at this method already in the process of obtaining of films, there is partial decomposition of high temperature b.c.c. $\beta$-phases with formation of mixture of b.c.c. $\beta$-, f.c.c. $\alpha$ - and f.c.c. $\gamma_{2}$-phases $[43,44]$. 
In such thin films (thickness $\cong 100 \mathrm{~nm}$ ), high-temperature $\beta$-phase usually ordered at a room temperature is in the disordered state that can be conditioned by the small size of grains $(10-50 \mathrm{~nm})$. Martensitic transformation in films with such size of grains does not take place. Heating to the high temperatures causes growth of grains. At cooling, there is ordering of high temperature phase and reversible MT. Partial decomposition of $\beta$-phase with formation of $\alpha$ - and $\gamma_{2}$-phases proceeding in the process of deposition causes the change of composition and increase of martensitic point. It is necessary also to mark the change of morphology of martensite arising up in such films. Instead of the usually observed needle-shaped crystals in films obtained with thermal evaporation, martensite appears as thin plates, which form packages on more late stage of transformation.

For the obtaining of thin films, the method of magnetron deposition is widely used also. It is possible to obtain films by this method in thick from $0.5 \mu \mathrm{m}$ and higher and with high enough composition homogeneity degree. However, quality and capacity (properties) of these films substantially depend on the conditions of deposition (temperature, velocity of evaporation, thickness, and kind of substrate), composition of initial alloy and type of the following heat treatment.

In the micromechanism of different type and assignment applied in different areas, thin films obtained by the methods of magnetron deposition of the $\mathrm{Ti}-\mathrm{Ni}$ and $\mathrm{Ti}-\mathrm{Ni}-\mathrm{Me}(\mathrm{Me}=\mathrm{Cu}, \mathrm{Fe}, \mathrm{Co}, \mathrm{Pd})$ alloys are most often used. Alloying allows changing of temperature intervals and hysteresis of the martensitic transitions. In the films obtained by magnetron deposition of initial equiatomic alloys of $\mathrm{Ti}-$ $\mathrm{Ni}$, the concentration of $\mathrm{Ni}$ is always enhanced. Additional films of Ti deposited on the target allow obtaining compositions with $\mathrm{Ni}$ in the interval 45-53 at.\% [45]. If deposition is fulfilled on cold substrate, the films are obtained in the amorphous state and, only at heating higher $500^{\circ} \mathrm{C}$, crystallization takes place. A structure and state substantially depend also on pressure of Ar in a chamber and type of substrate. Most often glass, plates of copper or silicon use as substrate.

At cooling of crystalline films of $\mathrm{Ti}-\mathrm{Ni}$ alloys obtained by magnetron deposition, those phases appear that are in the massive state. So, in the $\mathrm{Ti}-51.9$ at.\% $\mathrm{Ni}$ alloy after annealing at $500^{\circ} \mathrm{C}$ from the ordered $B 2$-phase with the lattice parameter $a_{B 2}=0.3012 \mathrm{~nm}$ during lowering of the temperature two phases arise: rhombohedral $R$ phase (lattice parameter $a_{R}=0.3012 \mathrm{~nm}$, rhombohedral angle $\alpha=$ $=89.53^{\circ}$ ) and monoclinic $M$-phase (lattice parameters: $a=0.2883$ $\mathrm{nm}, b=0.4121 \mathrm{~nm}, c=0.4909 \mathrm{~nm}, \beta=96.54^{\circ}$ ) $[45,46]$. A rhombohedral angle of $R$-phase depends on the temperature of annealing 
and decreasing with lowering of the temperature. Thus, the parameters of phases arising in the crystalline thin films substantially do not differ from the parameters of these phases appearing in $\mathrm{Ti}-\mathrm{Ni}$ alloys of the same composition in the massive state.

In the $\mathrm{Ti}-51.3$ at. $\% \mathrm{Ni}$ alloy during annealing in the interval of temperatures $300-500^{\circ} \mathrm{C}$, sizes of grains are not changed (about 1 $\mu \mathrm{m})$ and there is formation of needle-shaped $\mathrm{Ti}_{3} \mathrm{Ni}_{4}$ particles [46]. Their size substantially depends on temperature and time of aging and can run up to $460 \mathrm{~nm}$ after annealing at $500^{\circ} \mathrm{C}$ during $100 \mathrm{~h}$. The low-limit of these particles is observed after annealing at $400^{\circ} \mathrm{C}$ during $1 \mathrm{~h}$ and reaches to $10 \mathrm{~nm}$. As well as in the massive materials, the particles of $\mathrm{Ti}_{3} \mathrm{Ni}_{4}$ are located in the $\{111)_{B 2}$ planes along directions $\langle\mathbf{1 1 0}\rangle_{B 2}$. Increase of duration of annealing at $500^{\circ} \mathrm{C}$ in $\mathrm{Ti}-$ 51.9 at. \% $\mathrm{Ni}$ results in the increase of the beginning temperatures of formation $R$ - and $M$-phases and temperatures of the reverse transitions $M \rightarrow B 2$ and $R \rightarrow B 2$.

In the deposited films of $\mathrm{Ti}-43.9$ at.\% $\mathrm{Ni}$ alloy, transformation at both cooling and heating takes place in two stages, through $R$ phase [46]. The size of grains in such films changes from $0.5 \mu \mathrm{m}$ to a few $\mu \mathrm{m}$. Annealing at $500^{\circ} \mathrm{C}$ during time, which does not exceed $10 \mathrm{~h}$, changes the temperatures of $B 2 \rightarrow R \rightarrow M$ and $M \rightarrow R \rightarrow B 2$ transitions. Dependences of temperature beginning of the direct MT $M_{\mathrm{s}}$ in thin films of $\mathrm{Ti}-51.9$ at.\% $\mathrm{Ni}$ and $\mathrm{Ti}-43.9$ at.\% $\mathrm{Ni}$ alloys on aging time at $500^{\circ} \mathrm{C}$ resulted in Fig. 7 .

In the case of deposition on cold substrate (including room temperature), the films of $\mathrm{Ti}-\mathrm{Ni}$ alloys appear in the amorphous state. During crystallization, the equilibrium state arises in alloys only in

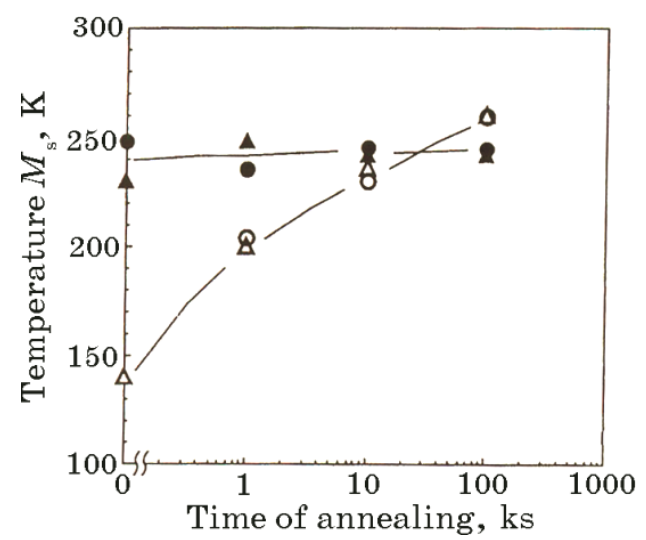

Fig. 7. The dependence of temperature of beginning of the direct $\mathrm{MT} M_{\mathrm{s}}$ on annealing time at $500^{\circ} \mathrm{C}$ for alloys $\mathrm{Ti}-51,9$ at. $\% \mathrm{Ni}(\circ, \triangle)$ and $\mathrm{Ti}-$ 43,9 at. $\% \mathrm{Ni}(\Delta, \bullet)$ measured by methods of DSC $(\circ, \Delta)$ and by mechanical tests $(\triangle, \bullet)[46]$. 
the concentration interval $49.5-50.5$ at. $\%$ of $\mathrm{Ni}$. In $\mathrm{Ti}$ - or $\mathrm{Ni}$ enriched alloys, appearing state is not equilibrium. Therefore, during crystallization of the amorphous thin films, excepting equilibrium equiatomic phase, non-equilibrium TiNi phases and states can arise [46]. Their structure appears clearly during investigations by the methods of high-resolution electron microscopy. For example, in the $\mathrm{Ti}-48.3$ at. $\% \mathrm{Ni}$ alloy after annealing at $600^{\circ} \mathrm{C}$ during $1 \mathrm{~h}$, there were found very thin disc-like Ti-enriched particles having $0.5 \mathrm{~nm}$ thickness and 5-10 nm radius. Diffraction patterns from these particles correspond to the crystalline structure of the hightemperature B2-phase. Particles are located in the planes of $\{100\}_{B 2^{-}}$ type along the directions $[010]_{B 2}$ and $[001]_{B 2}$, and bring to appearance of streaks in these directions on the corresponding microdiffraction systems [47]. Disc-like particles are the result of formation of Guinier-Preston zones. They appear on the boundaries of crystalline domains arising during crystallization of amorphous films. The spherical particles of $\mathrm{Ti}_{2} \mathrm{Ni}$ measured to $20 \mathrm{~nm}$ and distributed arbitrary in B2-phase are found out too. These particles are partly coherent with a matrix [47].

If aging of the Ti-enriched films of the Ti-Ni (47.3 or 48.2 at.\% of $\mathrm{Ni}$ ) or $\mathrm{Ti}-43.0 \% \mathrm{Ni}-6.2 \% \mathrm{Cu}$ (at.\%) alloys obtained by deposition carried out at a crystallization temperature or below by $50^{\circ} \mathrm{C}$, thin (0.5-1.5 $\mathrm{nm}$ in thick) plate-like coherent with matrix particles appear [48]. Their crystalline structure corresponds to b.c.t. lattice with the high degree of tetragonality: $c / a=1.1-1.4$. Such plate-like particles result in appearance around them fields of large elastic deformations. By opinion of authors, such particles increase amount of the reversible deformation conditioned by the martensitic transformation.

The Guinier-Preston zones (seen as thin plate particles in a few atomic layers thick) at the increase of temperature or duration of annealing grow in a size, their number is increased also [49]. Zones have influence on subsequent MT changing the microstructure of martensitic plates-type of twins appearing in the plates of martensite. Correlation of widths of twin constituents is changed also in a martensite.

In the martensite of the equiatomic $\mathrm{Ti}-\mathrm{Ni}$ alloys (or near to them by composition), the Guinier-Preston zones do not appear; there are twins of a $\langle 011\rangle$ type. However, in thin plates of martensite appearing in the $\mathrm{Ti}-\mathrm{Ni}$ alloys enriched by $\mathrm{Ti}$ appearance of twins is possible on a plane (11 $\overline{1})$. At a sufficient width and number of the Guinier-Preston zones, compound twinning in a martensite takes place on a plane (001) [49].

Investigation of the MT parameters in deposited films of $\mathrm{Ti}-$ 50 at. $\% \mathrm{Ni}$ alloy allowed to determined dependence of the trans- 


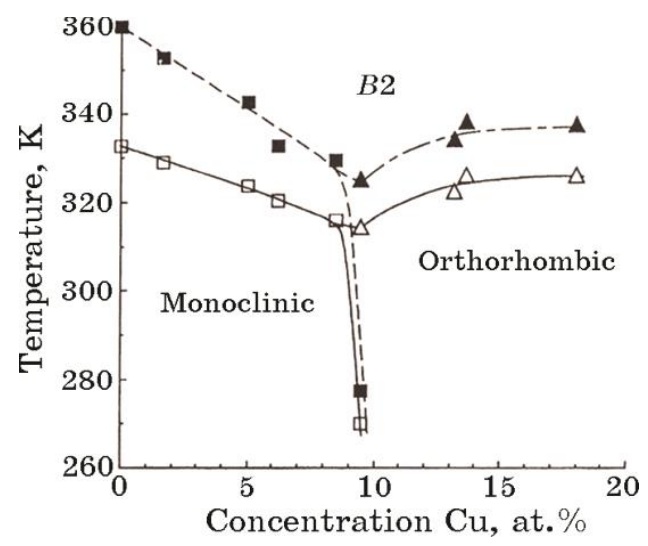

Fig. 8. Dependence of peak temperatures of direct $\leftrightarrow$ reverse MT measured by the DSC method on $\mathrm{Cu}$ concentration in thin films of $\mathrm{Ti}-\mathrm{Ni}-\mathrm{Cu}$ alloys [46]. $\quad B 2 \leftrightarrow$ monoclinic: a-austenitic phase, $\square$-martensite phase; $B 2 \leftrightarrow$ orthorhombic: $\mathbf{\Delta}$-austenitic phase, $\triangle$-martensite phase.

formation temperatures on the thickness of film [50]. At thicknesses less than $1 \mu \mathrm{m}$, characteristic temperatures are lowered, but decreasing largely depends on the state of surface. In the case of presence of oxide film, there is decreasing of the transition temperatures approximately on $50^{\circ} \mathrm{C}$.

In deposited films of $\mathrm{Ti}-\mathrm{Ni}-\mathrm{Cu}$ alloys, those monoclinic and orthorhombic martensitic phases appear in the massive samples of this composition [46]. The dependence of the characteristic transformation temperatures on copper content is presented in Fig. 8. The size of transformation hysteresis also depends on the concentration of copper in these alloys. Such dependence manifests itself most strongly in area of the single-phase $B 2 \rightarrow M$ transition. With increase of $\mathrm{Cu}$ concentration from 0 to 9.5 at.\%, the hysteresis at this transformation is changed from $27 \mathrm{~K}$ to $9.5 \mathrm{~K}$. In the range of two-phase transitions, dependence of hysteresis on $\mathrm{Cu}$ concentration in an alloy is substantially less.

Considering the MT peculiarities in thin films obtained magnetron deposition, influences of thickness on such transitions, and their distinctions with the peculiarities of MT in used for deposition massive specimens (alloys), it is always needed to take into account the possibility of change the concentration of elements constituting the alloy. For example, in [51], it was shown that at magnetron deposition of $\mathrm{Ti}_{50.5} \mathrm{Ni}_{44.99} \mathrm{Cu}_{4.96}$ alloy on substrate with a temperature below $100^{\circ} \mathrm{C}$ obtained films by $1.5-6.0 \mu \mathrm{m}$ thick had composition: $\mathrm{Ti}_{47.5} \mathrm{Ni}_{47.5} \mathrm{Cu}_{5.0}$. In such alloy, instead of single $B 2 \rightarrow M$ phase transition MT during cooling proceeds through $R$-phase. At a room temperature, there were found out the enriched by $\mathrm{Cu}$ particles of 
$\mathrm{Ti}_{0.33} \mathrm{Ni}_{0.43} \mathrm{Cu}_{0.24}$ with a tetragonal structure (lattice parameters: $a=$ $=0.31 \mathrm{~nm}, c=0.80 \mathrm{~nm})$. Such particles appear as thin rectangles, have a size of $100 \mathrm{~nm}$ in a long direction, semi-coherent interphase boundary with $B 2$ phase and orientation $\{100\}_{B 2}$. Arising as a result of discrepancy on the interphase boundary of particles of $\mathrm{Ti}-(\mathrm{Ni}+$ $+\mathrm{Cu})_{2}$ stress (deformations) brings to the increase of temperature of the formation beginning of the phase arising before martensitic one and appearance of preferable places of its heterogeneous origin. A martensitic phase appears below $-110^{\circ} \mathrm{C}$ as thin plates.

A size effect was also observed in deposited films of $\mathrm{Ni}-\mathrm{Mn}-\mathrm{Sn}$ alloys in which the ferromagnetic shape memory effect takes place in the massive state [52]. In these alloys, the influence of grain size on proceeding of MT found out also. At the grain sizes lesser than $10.8 \mathrm{~nm}$, transformation does not take place, an parent phase remains stable at all temperatures. The observations showed that growth of martensitic plates was stopped on the grain boundaries.

In the films of $\mathrm{Cu}-26.9 \% \mathrm{Al}-5.5 \% \mathrm{Ni}($ at. $\%$ ) alloy (thickness of $3 \mu \mathrm{m}$ ) obtained by magnetron deposition on glass or Si(100) substrate with the grain size of a few nanometres, the textured b.c.c.structure and three variants of the hexagonal structure coexist at a room temperature (hexagonal structure in the copper-based alloys presents usually as orthorhombic one) [53]. There are stacking faults in a hexagonal phase. Crystal lattices of founded phases have the followings parameters: $a_{\text {b.c.c. }}=0.298 \mathrm{~nm}, a_{2 H}=0.45 \mathrm{~nm}, b_{2 H}=$ $=0.52 \mathrm{~nm}, c_{2 H}=0.422 \mathrm{~nm}$ that is the same parameters as well as in the massive alloys of this composition. A difference consists of that all arising up in thin films phases are disordered. Another peculiarity of the obtained films consists of that they are brittle one and shape-memory effect (SME) absents in such films. After heating to $750^{\circ} \mathrm{C}$ and aging during $60 \mathrm{~min}$ in subsequent quenching to $20^{\circ} \mathrm{C}$, grain size is increased to $300 \mathrm{~nm}$ and martensite appears with $18 R$ structure. The shape memory effect proceeds in this state. However, recover of initial size and state at heating higher $A_{\mathrm{f}}$ is only partial that can be conditioned some deformation of martensitic phase at loading in the process of SME investigations.

Martensitic transformation in films obtained by quenching from liquid state. For the obtaining of thin films (ribbons), the method of quenching from the liquid state (melt) is used sufficiently frequently. By use this method, it is possible to obtain the cooling velocity of $10^{4}-10^{8} \mathrm{~K} / \mathrm{s}$ and to obtain films of $40-100 \mu \mathrm{m}$ thick. Because of the high cooling rate, there is often amorphous state and a small thickness stipulates the range of peculiarities in proceeding of the phase (and martensitic) transformations after crystallization. Stress arising during high-rate quenching results in essential change of the imperfect structure: formation of high-density of dis- 
locations and vacancies. In addition, during crystallization of the amorphous films often there is a fine-grained structure. Such structural states render substantial influence on proceeding of martensitic and other phase transitions in films obtained by the high-rate quenching from the melt.

Already in the first works on investigations of MT peculiarities in such samples, it was shown that, at the quenching rate of $10^{7}$ $\mathrm{K} / \mathrm{s}$ in foils of $\mathrm{Au}-50$ at. $\% \mathrm{Cd}$ alloy, the temperature of starting of transition of the parent $\beta$ phase into martensitic one is decreased and, for the starting of transformation, a tempering at room temperature is required [54]. Authors explain the delay of MT at quenching with formation of high concentration of vacancies annihilating on dislocations where formation of nuclei of martensitic phase can be. About influence of high concentration of vacancies arising in films of $\mathrm{Cu}-11.7 \% \mathrm{Al}-3.5 \% \mathrm{Ni}$ (wt.\%) alloy (obtained by the velocity quenching $10^{6} \mathrm{~K} / \mathrm{s}$ from the liquid state) on the temperatures of direct-reverse martensitic transformation it is also reported in [55].

In the films of $\mathrm{Cu}-\mathrm{Sn}$ alloys obtained by quenching from the liquid state with rates of $10^{6}-10^{7} \mathrm{~K} / \mathrm{s}$, MT arresting was not succeeded [56]. It can be related to the change of the alloy composition at quenching-by formation during quenching of extractions enriched with $\mathrm{Sn}$ and as a result by increase of the temperature of beginning of MT. The fulfilled electron-microscopy investigations showed that in grains less than $1 \mu \mathrm{m}$ martensitic crystals ( $\beta^{\prime}$ - and $\beta^{\prime \prime}$-phases) do not appear. Morphology and substructure of crystals of martensite arising in the films at this receipt method practically does not differ from such in crystals appearing in massive samples quenched by ordinary speeds. Substantially smaller sizes of the crystals are observed in the films obtained by high-rate quenching from the melt and are conditioned by small sizes of grains and simultaneous formation and growth of many martensitic plates during high-rate cooling.

The method of the high-rate quenching from the melt was widely used for obtaining of thin films (ribbons) of $\mathrm{Ti}-\mathrm{Ni}$ and $\mathrm{Ti}-\mathrm{Ni}-\mathrm{Me}$ $(M e=\mathrm{Cu}, \mathrm{Fe}, \mathrm{Co}, \mathrm{Hf})$ alloys. Enhanced interest to these alloys is conditioned not only the features of proceeding of the phase (and martensitic including) transitions but also their practical wide use as the alloys with unusual mechanical properties conditioned by MT. We will consider only those peculiarities of MT in these films, which are conditioned by the method of obtaining and by the influence of sizes (thicknesses) on these features.

At first, we will note two main peculiarities observed at the use of the ultrafast quenching from melt: formation of films (ribbons) of $\mathrm{Ti}-\mathrm{Ni}$ and $\mathrm{Ti}-\mathrm{Ni}-\mathrm{Cu}$ alloys in the amorphous state and lowering 
of temperatures MT [57-59]. The amorphous state arises only at certain conditions: quenching rates must be higher than $10^{6} \mathrm{~K} / \mathrm{s}$ and concentrations of copper (entered in alloy instead of nickel) more than 15 at.\%. The change of temperatures and intervals of the direct-reverse MT is conditioned not only a size factor but also origin in the alloys of high concentration of vacancies at ultrafast quenching. As electron-microscopy and diffraction investigations showed, tempering in the interval $500-700^{\circ} \mathrm{C}$ of temperatures results in ordering of such vacancies and formation of the long-period f.c.c. $x$-phase with the lattice parameter $a_{x}=1.58 \mathrm{~nm}[60,61]$.

Investigations carried out using thin ribbons of $\mathrm{Ti}_{50} \mathrm{Ni}_{50-x} \mathrm{Cu}_{x}$ $(x=5-32$ at. $\%)$ alloys obtained at rates of quenching from the liquid state of $10^{4}-10^{6} \mathrm{~K} / \mathrm{s}$ allowed to define influence of the quenching rate, composition and thickness on characteristic temperatures, intervals and hysteresis of the martensitic transitions and also on phase composition of appearing films [59, 62-64]. In this concentration range as well as in the massive specimens of alloys of such composition, the following phases appear b.c.c. B2, rhombohedral $R$, monoclinic $B 19^{\prime}$ and rhombic $B 19$. Amount of one or other phase is determined by composition, thickness of film and cooling temperature.

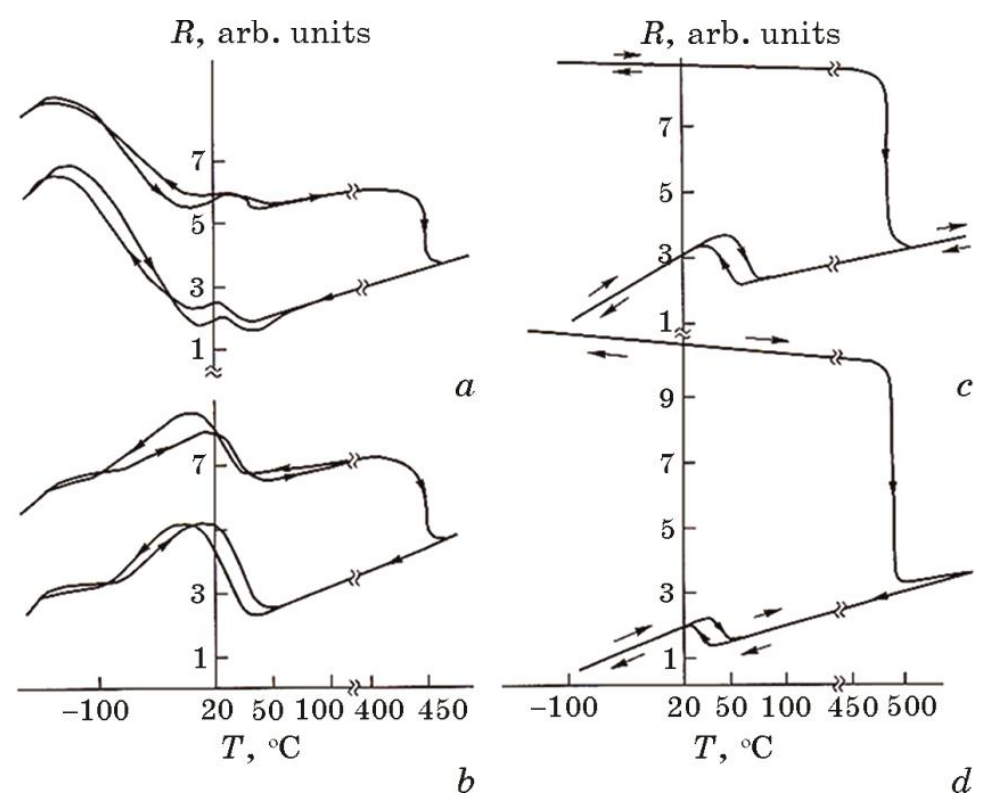

Fig. 9. Temperature dependences of electrical resistance in $\mathrm{Ti}_{50} \mathrm{Ni}_{50-x} \mathrm{Cu}_{x}$ alloys at $x=10(a), 15(b), 25(c)$ and $32(d)$ at.\%. Quenching rate (from the liquid state) is $10^{6} \mathrm{~K} / \mathrm{s}$ in $(a),(b)$-lower graphs are for samples after additional thinning [62]. 
In Figure 9, dependences of electrical resistance on a temperature are presented for the ribbons of $\mathrm{Ti}-\mathrm{Ni}-\mathrm{Cu}$ alloys containing the different amount of copper. All mentioned phases appear only in the alloy with 15 at.\% $\mathrm{Cu}$ and there is the following sequence of phase transitions: $B 2 \leftrightarrow R \leftrightarrow B 19^{\prime} \leftrightarrow B 19$. Fully amorphous state arises in the alloys with copper concentration of 25 and 32 at.\% that is confirmed by $\mathrm{x}$-ray and microdiffraction researches. Crystallization takes place because of heating higher $430^{\circ} \mathrm{C}$ and amorphous state transfers to the crystalline $B 2$ phase. It should be noted that additional thinning of the ribbons (thickness $40-100 \mu \mathrm{m}$ ) to $5 \mu \mathrm{m} \mathrm{re}$ sults in the substantial lowering of characteristic temperatures of transformation (see Fig. 9). Morphology of martensitic crystals changes also in the thinned ribbons. In place of trihedral pyramids usually observed later in ribbons, the plates appear mainly that can be caused by the change of the stress state during MT in thin films.

The rounded crystalline areas in which MT proceeds with certain peculiarities appear during initial stages of crystallization: formation of crystals of martensite begins not from boundaries as it usually takes place in massive specimens but in a centre of rounded area. It can be related both to concentration homogeneity in the whole volume of alloy and on a boundary 'crystalline areaamorphous area' and with relaxed state of these boundaries. Another peculiarity of MT during the initial stages of crystallization is noticeable influence of size factor: in crystalline areas with a diameter less than 5-10 $\mu \mathrm{m}$, martensite crystals do not appear [65].

The use of high-resolution electron microscopy enabled to set the structure of interphase boundaries between amorphous and martensitic phases. With the ribbons of $\mathrm{NiTi}-\mathrm{Hf}_{40}$ alloys, it was shown that such boundaries are of high energy and have non-equilibrium configuration [66]. Some parts of these boundaries are not direct, have irregular configuration, other ones show up as zigzag lines. Analysis performed by the method of energy dispersible spectroscopy showed that concentration of $\mathrm{Ni}$ and $\mathrm{Ti}$ in amorphous phase and in martensite is different.

\subsection{Martensitic Transformation in Nanocrystals and Nanomaterials}

With martensitic transformation in little size subjects, for instance, nanocrystals and nanoparticles, decision influence render such factors as proceeding of accommodation during transition, relaxation of arising stress, presence or absence of different sort of defects and, naturally, size factor, influencing above all things on possibility of the formation of nuclei of new (martensitic) phase and its subsequent growth is demonstrated. The size of initial nanocrystals determines dimensions of arising martensitic crystals and their sub- 
structure that can be related to the peculiarities of relaxation of arising during MT stress determining the final microstructure of the crystals.

During studying of MT in ultra-small powders of some Fe-based alloys, it was ascertained that, at sizes $10-200 \mathrm{~nm}$, the stabilization of parent $\gamma$-phase took place and martensitic crystals did not appear [67-70]. Critical size of nanocrystals for beginning of MT depends on material and type of the MT-thermoelastic or going on with large hysteresis. It caused by different character of proceeding of accommodation processes during MT in rounded particles of investigated amorphous $\mathrm{Fe}-\mathrm{Ni}, \mathrm{Fe}-\mathrm{Ni}-\mathrm{B}$ and $\mathrm{Ni}-\mathrm{Ti}-\mathrm{Cu}$ alloys obtaining by quenching from the liquid state. Martensitic transformation does not take place in particles less than $100 \mathrm{~nm}$ in $\mathrm{Fe}-\mathrm{Ni}$ and less than $15 \mathrm{~nm}$ in $\mathrm{Ni}-\mathrm{Ti}-\mathrm{Cu}$ alloys [69].

Critical size for different MT in nanocrystals (rounded nanoparticles in an amorphous matrix) and nanocrystal binary almost equiatomic Ni-Ti alloys differs: for $B 2 \rightarrow R$ and $R \rightarrow B 19^{\prime}$ transformations in nanocrystals, they are 30 and $100 \mathrm{~nm}$ and, for the same transitions in nanocrystal alloys, are 5 and $60 \mathrm{~nm}$, respectively [70]. Authors suppose that this distinction is caused by different in size power barriers to these types of MT in this alloy and different character proceeding during MT occurring. In particles with a diameter less than $100 \mathrm{~nm}$, one variant of twinned martensite appears and at the sizes of particles more than $100 \mathrm{~nm}$ is observed two twinned variants of martensite formally named 'herringbone' martensite [71]. According to the authors' opinion, differences in morphology are caused by different proceeding of accommodation processes in the particles of different size. At herringbone morphology, the processes of relaxation of deformation energy arising up during transformation proceeds more easily. This relaxation takes place on the additional boundaries of appearing 'superfluous' twins. Since $B 2 \rightarrow R$ transition requires lesser transformation deformation, $R$ phase appears in nanoparticles with a size up to $15 \mathrm{~nm}$. B2-phase remains fully in smaller nanograins.

\section{CONCLUSION}

In a review, two problems important for understanding of mechanism and peculiarities of martensitic transformations are considered and discussed: formation of nuclei of martensite crystals and peculiarities of martensitic transition in the subjects of small dimensions.

It is difficult to understand substantial difference of morphological and structural peculiarities of martensitic phases in different materials without consideration and accounting of the mechanism 
of formation of the martensitic nuclei during change of external conditions-temperature and applied stress. Such properties conditioned by formation of martensitic phase determine strength, plasticity, shape-memory effect, superelasticity, and superplasticity. Structural states of parent and arising phases affect also the kinetic peculiarity of the martensitic transformation.

In the review, models and schemes of martensitic nuclei proposed by different authors are considered. They relate more frequently to concrete materials and definite types of martensitic transitions-Febased alloys or non-ferrous metals (mainly copper alloys) with b.c.c. $\leftrightarrow$ f.c.c., f.c.c. $\leftrightarrow$ h.c.p., and b.c.c. $\leftrightarrow$ orthorhombic transitions. Unfortunately, it is necessary to note that there is no one of works dealing with nucleus formation during MT, where clear definition of martensitic nucleus is considered. The questions arise as follow: is nucleus a some formation with the special distribution of atoms (different from the initial or arising states) or is needed to account that nucleus is an area with a certain characteristic imperfect structure typical for each material ready to transform during the change of external conditions-temperature and magnitude of applied stress? Neither clear determinations nor exhaustive answers are proposed in the considered works.

In a number of works, it is assumed existence of certain areas with a structure similar to the structure of the phase appearing in the parent one. Growth of the martensite crystals starts from these areas. Areas can arise up because of change of temperature, for example, during quenching or at decomposition of parent phase, which are going on at quenching. Existence of such areas (with the structure of new phase?) is indirectly confirmed, for example, in carried out microstructure investigations with the $\mathrm{CuAlNi}$ alloys [72]. Authors found out the presence of some own 'memory' of the martensitic nuclei (some ready places): if, during the reverse transformation, there is no overheating a specimen substantially higher than temperature of the end of the reverse MT, during subsequent repeated lowering of the temperature, martensitic crystals arise in those places that at the first cooling. Thus, this can be concentration heterogeneity or certain kind of defects preserved during changes of the temperature below $200^{\circ} \mathrm{C}$. In a number of alloys, especially of copper-based, e.g., CuAlNi(Mn), CuZnAl, CuSn, in the process of quenching, there are concentration changes (e.g., due to formation of inclusions), which can result in the appearance of the first martensite crystals in these places (see Ref. [29]).

Presence of the special type of dislocations, their determined distribution and interaction are assumed in the proposed dislocation models of formation of the martensitic nuclei. There is both the splitting of complete dislocations and the formation of partials at 
some conditions. Because of their moving, there is a change of the crystal structure of the parent phase by the martensitic phase in this area. An important condition for the further reconstruction and proceeding of the phase transformation is a necessity of appearance of special interphase boundary with a certain structure dividing the parent and appearing phases. An arising interphase boundary must be coherent or consisting of coherent sections separated by the dislocations. Only in this case, it will possess high mobility, and growth of martensite crystal will be possible. However, many moving boundaries appear only in the case of the thermoelastic martensitic transformation.

Due to the lacks of the considered dislocation models of the nucleation of the martensitic phase, it is necessary to take into account their discrepancy with the following experimental facts. It is well known that additional annealing of the parent phase resulting in lowering of density of dislocations in material stipulates its stabilization that is considerable lowering of the temperature of the MT starting proceeds. It is also possible the braking of MT and preserving of the parent phase, though certain amount of dislocations is retained after annealing. At the same time, the MT promotes small deformations $(5-15 \%)$. It is related presumably to the formation of the certain-type dislocations located in the corresponding planes during the process of deformations. However, deformations higher $35-40 \%$, at which the dislocations' density and other defects rise, substantially break martensitic transition in most alloys, in which MT is possible at cooling. Thus, the role of dislocations in the process of formation of nuclei of new phase and further proceeding of MT is ambiguous enough. Apparently, for the starting of MT, the special type of dislocations, their special location (in certain crystallographic planes), possibility of splitting, moving, and interaction with other defects, including dislocations, is required.

In each proposed model, the mechanism of growth of appearing nucleus and specific type of interphase boundary between the parent and arising phases, which must possess high mobility for occurring of further transformation, is required. However, such mechanism is absent in many models.

Thus, in every case of the nucleation at MT, it is necessary to examine the type of initial crystal structure, transition conditions, possible and necessary (for splitting) type of dislocations, mechanism of their splitting and interaction during formation of martensitic nucleus as well as mechanism of growth of the martensite crystals taking into account the structure of the interphase boundary. Apparently, development of universal mechanism of formation of nuclei for all types of MT is hardly possible in any event in nearest future. 
The problem of martensitic transformation in the subjects of small dimensions is concerned with a question about the nucleation of the martensite. The MT in these subjects is strongly dependent on dimensions (thickness, diameter, size of the transformed volume), i.e., on the correlation of size of new-phase nucleus and dimensions of these subjects. In the subjects of small dimensions, the MT can take place with some peculiarities in some cases. The stage of nucleus formation at its some sizes is absent, or the number of nuclei is limited. In small particles, dislocations and other defects can be absent too. Since often there is no separating over grains in such subjects, the influence of grain boundaries on the processes of martensitic transition is absent. During MT in these materials, the role of the surface increases considerably, but stress effect can be absent or do not rise. The peculiarities of MT in subjects of small sizes are following: decreasing of the transition temperatures, change of the transformation intervals, value of the hysteresis, partial proceeding of MT. Influence of inhomogeneity on transition is increasing. Appearing martensite often has morphological peculiarities as compared to the crystal forms of the martensite in bulky specimens. The thin (sub)structure of the martensite crystals and crystallography of transformation can also change, in particular, the change of the mutual orientation of the parent and martensitic phases takes place. Stabilization of the parent phase in most materials occurs at the sizes of 10-200 $\mathrm{nm}$. A critical size depends on material, in which there is the MT, type of transition, conditions of occurring of the transformation, relaxation degree of arising stress.

\section{REFERENCES}

1. V. A. Lobodyuk, Fiz. Met. Metalloved., 99, No. 2: 29 (2005) (in Russian)

2. V. A. Lobodyuk and E. I. Estrin, Martensitnye Prevrashcheniya [Martensitic Transformations] (Moscow: Fizmatlit: 2009) (in Russian).

3. A. Z. Seeger, Metallk., 44: 247 (1953).

4. G. V. Kurdjumov, Journ. Techn. Fiz., XVIII: 999 (1948) (in Russian).

5. V. I. Danilov, Problemy Metallovedeniya i Fiziki Metallov [Problems of Physical Metallurgy and Physics of Metals] (Moscow: Metallurgizdat: 1949), p. 7 (in Russian).

6. S. R. Pati and M. Cohen, Acta Met., 17: 189 (1969).

7. $\quad$ H. Knapp and U. Dehlinger, Acta Met., 4: 289 (1956).

8. V. Raghavan and M. Cohen, Acta Met., 20: 333 (1972).

9. G. B. Olson and M. Cohen, Metallurg. Trans., 7A: 1897, 1905, 1915 (1976).

10. A. J. Bogers and W. G. Burgers, Acta Met., 12: 255 (1964).

11. P. L. Ferraglio and K. Mukherjee, Acta Met., 22: 835 (1974).

12. S. Dash and N. Brown, Acta Met., 14: 595 (1966).

13. M. Suezawa and H. E. Cook, Acta Met., 28: 423 (1980).

14. K. E. Easterling and A. R. Thölén, Acta Met., 24: 333 (1976). 
15. T. Suzuki, H. Kojima, K. Suzuki, T. Hashimoto, and M. Ichihara, Acta Met., 25: 1151 (1977).

16. G. Ghosh and V. Raghavan, Mater. Sci. and Eng., 80: 65 (1986).

17. J. Gaggero and D. Hull, Acta Met., 10: 995 (1962).

18. S. Dash and N. Braun, Acta Met., 14: 595 (1966).

19. Q. Chen, C. Sang, X. Wu, and J. Ke, Science of China E, 40: 387 (1997).

20. V. A. Lobodyuk, V. K. Tkachuk, and L. G. Khandros, Fiz. Met. Metalloved., 33, No. 1: 137 (1972) (in Russian).

21. K. P. Staudhammer, L. E. Murr, and S. S. Hecker, Acta Met., 31: 267 (1983).

22. M. O. Aboelfotoh, H. A. Aboelfotoh, and J. Washborn, J. Appl. Phys., 49: 5230 (1978).

23. W. Zhang, Y. M. Jin, and A. G. Khachaturyan, Phil. Mag., 87: 1545 (2007).

24. C. L. Magee, $A S M$, 115: 1 (1970).

25. M. A. Meyers, Metallurg. Trans., 10A: 1723 (1973).

26. V. A. Lobodyuk, Fiz. Met. Metalloved., 96, No. 6: 46 (2003) (in Russian).

27. K. Ogawa and S. Kajiwara, J. Jap. Inst. Met., 69: 1089 (2005).

28. A. Ibarra, D. Callard, and J. San Juan, Appl. Phys. Letters, 90: 76 (2007).

29. V. A. Lobodyuk, V. K. Tkachuk, and L. G. Khandros, Martensitnye Prevrashcheniya [Martensitic Transformations] (Kyiv: Naukova Dumka: 1978), p. 197 (in Russian).

30. A. Ignatiev, R. Aksenz, and B. W. Lee, Proc. $7^{\text {th }}$ Intern. Vac. Congr. and $3^{\text {rd }}$ Intern. Conf. Solid Surfaces (Sep. 12-16, 1977) (Vienna: 1977), p. 2435.

31. R. Aksenz, B. W. Lee, A. Ignatiev, and M. A. Van Hove, Solid State Communs., 25: 641 (1978).

32. R. Huizing and J. A. Klostermann, Acta Met., 14: 1693 (1966).

33. K. E. Easterling and P. R. Swann, Acta Met., 19: 117 (1971).

34. N. Ishikawa and A. Sato, Phil. Mag. A, 64: 387 (1991).

35. A. R. Thölén, Phil. Mag. A, 53: 259 (1986).

36. R. Monzen, A. Sato, and T. Mori, Acta Met., 14: 1267 (1966).

37. A. Couture and R. Angers, Met. Trans. A, 17: 37 (1986).

38. P. T. Cardew, R. J. Davey, and A. J. Ruddick, J. Chem. Soc. E. Symposium Series, 69: 123 (1973).

39. B. Yuan, C. Y. Chung, and M. Zhu, Mater. Sci. and Eng. A, 382: 181 (2004).

40. A. A. Klopotov, V. P. Sivocha, N. M. Matveeva, and Yu. A. Sazanov, Russ. Phys. Journ., 36: 526 (1993).

41. T. Saburi, T. Komatsu, S. Nenno, and Y. Watanabe, J. Less-Common Metals, 118: 217 (1986).

42. S. Morito, T. Moritani, T. Furuhara, and T. Maki, Mater. Sci. Forum, 327328: 207 (2000).

43. V. A. Lobodyuk, L. Ya. Sadykova, and T. M. Yusupov, Metallofizika, 10: 69 (1988) (in Russian).

44. V. A. Lobodyuk, Fiz. Met. Metalloved., 110, No. 3: 232 (2010) (in Russian).

45. S. Miyazaki, K. Nomura, and A. Ishida, J. de Physique IV. Colloque C8, Suplement au J. de Physique III, 5: C8-667 (1995).

46. S. Miyazaki and A. Ishida, Mater. Sci. and Eng. A, 273-275: 106 (1999).

47. A. Ishida and S. Miyazaki, Mater. Sci. and Eng. A, 273-275: 754 (1999).

48. T. Matsunaga, S. Kajiwara, K. Ogawa, T. Kikuchi, and S. Miyazaki, Mater. Sci. and Eng. A, 273-275: 745 (1999).

49. J. X. Zhang, M. Sato, and A. Ishida, Acta Materialia, 49: 3001 (2001). 
50. A. Ishida and M. Sato, Acta Materialia, 51: 5571 (2003).

51. L. Chang and D. S. Grummon, Scr. Metallurg. et Materialia, 25: 2079 (1991).

52. R. Vishnoi and D. Kaur, Surface and Coating Technology, 204: 3773 (2010).

53. F. C. Lovey, A. M. Condo, J. Guimpel, and M. J. Yacaman, Mater. Sci. and Eng. A, 481-482: 426 (2008).

54. P. L. Ferraglio, K. Mukherjee, and K. S. Castleman, Acta Met., 18: 1067 (1970).

55. J. V. Wood, MRS Proceedings, 28: 425 (1983).

56. V. A. Lobodyuk and V. K. Tkachuk, Izvestiya AN SSSR. Metally, No. 2: 105 (1978) (in Russian).

57. N. M. Matveeva, Yu. K. Kovneristyy, L. A. Matlakhova, Z. G. Fridman, and M. A. Lobzov, Metally, No. 4: 97 (1987) (in Russian).

58. N. M. Matveeva, V. A. Lobodyuk, V. I. Kolomytsev, and I. D. Lovtsova, Izvestiya AN SSSR. Metally, No. 3: 164 (1991) (in Russian).

59. M. B. Babanly, V. A. Lobodyuk, and N. M. Matveeva, Izvestiya AN SSSR. Metally, No. 2: 171 (1993) (in Russian).

60. V. I. Kolomytsev, V. A. Lobodyuk, and L. G. Khandros, phys. stat. sol. (a), 50: K127 (1978).

61. V. I. Kolomytsev, V. A. Lobodyuk, and L. G. Khandros, phys. stat. sol. (a), 65: 87 (1981)

62. M. B. Babanly, V. A. Lobodyuk, and N. M. Matveeva, Fiz. Met. Metalloved., 75, No. 5: 89 (1993) (in Russian).

63. V. A. Lobodyuk, Metallofiz. Noveishie Tekhnol., 20, No. 2: 56 (1998) (in Russian).

64. V. A. Lobodyuk, Metallofiz. Noveishie Tekhnol., 27, No. 9: 1193 (2005) (in Russian).

65. V. A. Lobodyuk, Fiz. Met. Metalloved., 86, No. 3: 123 (1998) (in Russian).

66. M. Liu, X. M. Zhang, Y. Y. Li, Z. Chen, and M. J. Tu, J. Alloys and Compounds, 334: 147 (2002).

67. S. Kajiwara, S. Ohno, and K. Honmo, Phil. Mag., 63: 625 (1991).

68. X. Zhao, X. Y. Liang, Z. Hu, and B. Lio, Jap. J. Appl. Phys., 35: 4468 (1996).

69. A. M. Glezer, E. N. Blinova, V. A. Pozdnyakov, and A. V. Shelyakov, J. Nanoparticle Research, 5: 551 (2003).

70. T. Waitz and H. R. Karnthaler, Acta Mater., 52: 5461 (2004).

71. T. Waitz, W. Pranger, T. Antretter, F. D. Fischer, and H. R. Karnthaler, Mater. Sci. and Eng. A, 481-482: 479 (2008).

72. G. V. Kurdjumov and L. G. Khandros, Doklady AN SSSR, LXVI: 211 (1949) (in Russian). 